\title{
Temperature extremes in Alaska: temporal variability and circulation background
}

\author{
Agnieszka Sulikowska $^{1}$ (D) Jakub P. Walawender ${ }^{2} \cdot$ Ewelina Walawender $^{1}$
}

Received: 14 December 2017 / Accepted: 29 May 2018 / Published online: 9 June 2018

(C) The Author(s) 2018

\begin{abstract}
The aims of this study are to characterize the spatial and temporal variability of extremely warm days (WDs) and warm spells (WSs) in summer as well as extremely cold days (CDs) and cold spells (CSs) in winter in Alaska in the years 1951-2015 and to determine the role of atmospheric circulation in their occurrence. The analysis is performed using daily temperature maxima $\left(T_{\mathrm{MAX}}\right)$ and minima $\left(T_{\mathrm{MIN}}\right)$ measured at 10 weather stations in Alaska as well as mean daily values of sea level pressure and wind direction at the $850 \mathrm{hPa}$ isobaric level.

WD (CD) is defined as a day with $T_{\mathrm{MAX}}$ above the 95 th $\left(T_{\mathrm{MIN}}\right.$ below the 5 th) percentile of a probability density function calculated from observations, and WS (CS) equals at least three consecutive WDs (CDs). Frequency of the occurrence and severity of warm and cold extremes as well as duration of WSs and CSs is analyzed. In order to characterize synoptic conditions during temperature extremes, the objective classification scheme of advection types considering jointly the direction of the air influx and type of pressure system is employed.

The results show that the general trend is towards the warmer temperatures, and the warming is greater in the winter than summer and for $T_{\mathrm{MAX}}$ as opposed to $T_{\mathrm{MIN}}$. This is reflected in changes in the frequency of occurrence and intensity of temperature extremes which are much more pronounced in the case of winter cold extremes (decreasing tendencies) than summer warm extremes (increasing tendencies).

The occurrence of temperature extremes is generally favored by anticyclonic weather with advection direction indicating air mass flows from the interior of the North American continent as well as the south (warm extremes in summer) and north (cold extremes in winter).
\end{abstract}

\section{Introduction}

Air temperatures have been observed to increase across the planet Earth since the late nineteenth century (IPCC 2013). This trend is particularly strong in the Arctic, where the warming occurs at roughly twice the rate of that at middle latitudes in the northern hemisphere (AMAP 2011; Walsh et al. 2011). The change in the distribution of mean annual air temperatures is also linked with a change in the distribution of air temperature extremes (IPCC 2013), which leads to a change in the frequency of extreme temperature events-

Agnieszka Sulikowska

a.sulikowska@doctoral.uj.edu.pl

Department of Climatology, Jagiellonian University, Kraków, Poland

2 Institute of Meteorology and Water Management - National Research Institute (IMGW-PIB), Kraków, Poland hereafter temperature extremes - or days with exceptionally high or low air temperatures as well as warm and cold spells. Humans, animals, and plants are sensitive to the severity, frequency, and persistence of extremes (Wigley 1985), which explains why these parameters are most often examined by climatologists.

Increases in the frequency of occurrence, duration, and severity of warm extremes along with a decrease in the case of cold extremes are observed on a global scale (Alexander et al. 2006; Perkins et al. 2012) as well as in particular regions of the Earth, especially at high latitudes of the northern hemisphere (AMAP 2011; IPCC 2013). Della-Marta et al. (2007) found that in the 1880-2003, the length of heatwaves doubled in Western Europe, while the occurrence of hot days nearly tripled. Tendencies noted in the USA vary by region; however, most areas of the country including Alaska have experienced warm spells and heatwaves more often since the 1950s, while cold spells have become less frequent (Barnett et al. 2012; Peterson et al. 2013). In Canada, in the period 1911-2010, 
warm and cold extremes became increasingly warmer, especially in the winter and in the Arctic regions of the country (Wang et al. 2014). Matthes et al. (2015) were able to document a clear and statistically significant decreasing trend in the frequency of cold spells in the Arctic in the winter and summer as well as less pronounced, seasonal, and regional tendencies (either positive or negative) in the frequency of the occurrence of warm spells (1979-2013). Research results based on climate scenarios show a continuation of currently noted tendencies in the future, both in North America and in Alaska alone (Lau and Nath 2012; Bennett and Walsh 2015; Jeong et al. 2016), as well as in other regions of the Earth (Meehl and Tebaldi 2004; Alexander et al. 2006; Vavrus et al. 2006; Kyselý 2010).

Alaska possesses a highly diverse climate due to its large geographic area $\left(1,525,953 \mathrm{~km}^{2}\right)$, meridional extent, long coastline on the one side, and the large landmass of the North American continent on the other side, as well as variable relief (Shulski and Wendler 2007; Bieniek et al. 2012). Many publications document an increase in air temperature at many weather stations in Alaska and for many different periods of time starting in the early twentieth century (Stafford et al. 2000; Wendler and Shulski 2009; Wendler et al. 2010a; Gil-Alana 2012; Bieniek et al. 2014; Wendler et al. 2016). Bieniek et al. (2014) estimated that a statewide average warming of about $1{ }^{\circ} \mathrm{C}$ occurred in the years 1920-2012; however, tendencies varied in sign and magnitude depending on the climate division, time of year, and particular 30-year sub-periods. In the first decade of the twenty-first century, a decrease in air temperature was noted in all regions of Alaska except its Arctic region, where an increasing trend continued to exist (Wendler et al. 2012; Bieniek et al. 2014).

Many research studies have also shown a significant effect of large-scale teleconnections such as the El Niño-Southern Oscillation (ENSO) and the Pacific Decadal Oscillation (PDO) on variability and trends in air temperature across Alaska, with the positive phase of both oscillations associated with higher than usual air temperatures (Mantua et al. 1997; Hess et al. 2001; Papineau 2001; Hartmann and Wendler 2005a; Bieniek et al. 2011). The variability of PDO, which follows a nearly 30 -year cycle, was also associated with a pronounced upward shift in seasonal and annual temperatures in 1976, as well as a decrease in air temperature in the first decade of the twenty-first century (Hartmann and Wendler 2005a; Wendler et al. 2012). Bieniek and Walsh (2017) have shown that the occurrence of monthly (1920-2012) and daily (1948-2012) air temperature extremes across Alaska is also strongly linked with changes in PDO, while Shulski et al. (2010) noted its strong significance in the emergence of two long-term and widespread winter temperature anomalies in the years 2002 and 2007.

Given the crucial importance of atmospheric circulation in weather patterns at middle and high latitudes (Huth et al.
2008; Kyselý 2008), attempts were made and continue to be made to assess its role in the occurrence of temperature extremes. Bieniek and Walsh (2017) have shown that the most relevant factor in the occurrence of temperature extremes in Alaska is the advection of air masses with specific temperature and moisture parameters along with effects produced by local topography and coastal features. Cassano et al. (2016a, b) were able to show that, in addition to advection, anomalously large surface downward shortwave radiation also often causes summer warm extremes, while winter cold extremes are facilitated by anomalous downwelling longwave radiation. As Cassano et al. (2016a, b) and Bieniek and Walsh (2017) have shown, warm (cold) extremes in Alaska are generally associated with synoptic patterns resulting in southerly (northerly) flow. In the case of summer warm spells and winter cold spells, blocking situations are of particular importance or the long-term hovering of high pressure systems, which limits the zonal flux of air masses over a given geographic area (Cattiaux et al. 2010, Schneidereit et al. 2012, Poręska and Zdunek 2013; Cassano et al. 2016a). Long-lasting cold spells in the winter are also facilitated by ground-level temperature inversions (Papineau 2001; Shulski et al. 2010), which were examined for the case of the city of Fairbanks in Alaska (Hartmann and Wendler 2005b).

The main purpose of this paper is to characterize the occurrence of summer warm extremes or extremely warm days (WDs) and warms spells (WSs) as well as winter cold extremes or extremely cold days (CDs) and cold spells (CSs) in Alaska in the years 1951-2015, and to discuss circulation conditions facilitating their occurrence. The specific goals of the study are:

- an assessment of multiannual variability and trends for maximum and minimum air temperature in the summer (JJA) and winter (DJF) and the occurrence of warm and cold extremes in a spatial context,

- characterization of warm and cold extremes in terms of severity and also WS and CS in terms of their duration,

- identification of main relationships between the occurrence of warm and cold extremes and the direction of air mass advection and atmospheric pressure patterns at sea level.

\section{Data}

The analysis in this study was performed using two independent datasets. The basic data unit consisted of daily temperature maxima $\left(T_{\mathrm{MAX}}\right)$ and minima $\left(T_{\mathrm{MIN}}\right)$ measured at 10 weather stations in Alaska (Fig. 1). These stations were selected on the basis of their record length and geographical location. They are quite evenly distributed across the state and represent different climate conditions, as well as reflect 


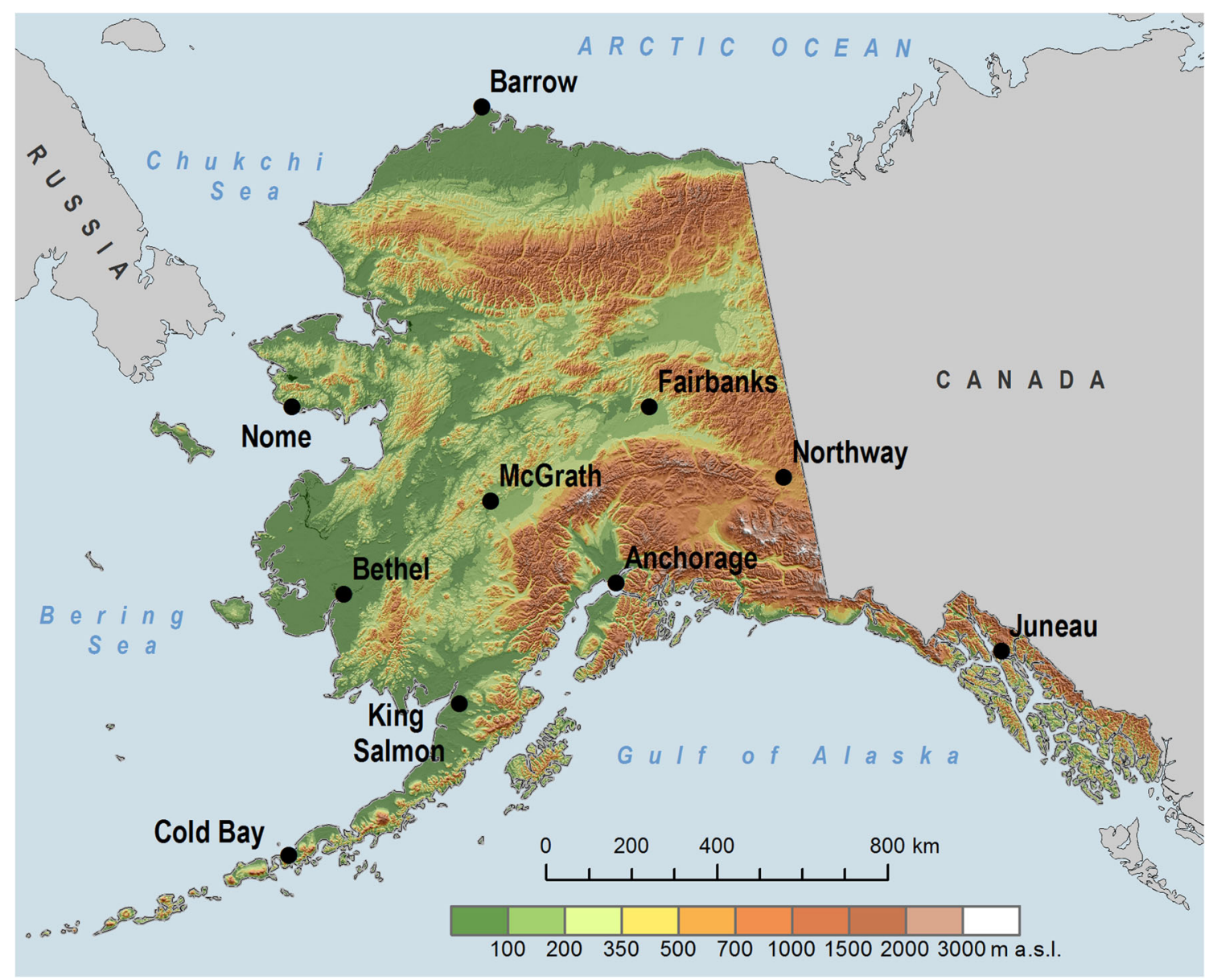

Fig. 1 Selected weather stations and land relief of Alaska

differences between maritime and continental climate regimes (Fig. 1). The number of stations was determined by the type of the study which focused on detailed analysis at individual locations. The data were obtained from the Global Summary of the Day (GSOD) dataset, which belongs to the US National Climatic Data Center (NCDC), for two seasons of the yearsummer (JJA) and winter (DJF) for the period of Jan. 1, 1951 to Feb. 29, 2016 (Jan. 1, 1953 to Feb. 29, 2016 for Anchorage). The data used in the study are quality-controlled. Gaps in the dataset for eight weather stations did not exceed $0.1 \%$. Gaps for Cold Bay equaled $1.6 \%$ due to a complete lack of data from July 1954 to June 1955. Gaps for Northway equaled 3.5\% due to a lack of data for August 1957 and from February 1971 to January 1973.

Mean daily values of atmospheric pressure at sea level and wind direction values at the $850 \mathrm{hPa}$ isobaric level were obtained from the North American Regional Reanalysis (NARR; Mesinger et al. 2006) dataset made available by the US National Oceanic and Atmospheric Administration/Oceanic and Atmospheric Research/Earth System Research Laboratory Physical Science Division (NOAA/OAR/ESRL PSD), Boulder, CO (http://www.esrl.noaa.gov/psd/). The data were obtained for grid points located nearest to each of
10 weather stations and for the longest available period of time (Jan. 1, 1979 to Jul. 31, 2015). The spatial resolution of the dataset was approximately $0.3^{\circ} \times 0.3^{\circ}(32 \mathrm{~km} \times 32 \mathrm{~km})$.

\section{Methods}

Temperature extremes are the subject of many studies; however, due to the multiplicity of groups and sectors affected negatively by them (i.e., human and animal health, agriculture, forestry, transportation), there are no universal methods for defining them (Perkins 2015). Air temperature thresholds above/below which a given value may be considered as extreme are identified via arbitrary or relative means. The former relies on assuming an air temperature threshold that is most often related to impacts (Stephenson 2008). The latter is based on a group of statistical methods - air temperature thresholds are identified via: (1) the multiannual mean plus the given value (e.g., $\mathrm{T}_{\mathrm{AVG}}+5{ }^{\circ} \mathrm{C}$; e.g., Shevchenko et al. 2014), (2) mean and multiple of the standard deviation (e.g., $\mathrm{T}_{\mathrm{AVG}}+\sigma$; e.g., Papineau 2001), (3) percentile-based thresholds (e.g., Perkins et al. 2012). Among the methods listed above, the most useful appears to be the last method in cases where 
temperature extremes are considered for a geographic area characterized by strongly variable climate conditions. In addition, this method is recommended by the IPCC (2013). In this study, WD is defined as a day with $T_{\text {MAX }}$ above the 95 th percentile and $\mathrm{CD}$ as a day with $T_{\mathrm{MIN}}$ below the 5 th percentile of a probability density function estimated from observations. To account for a seasonal cycle, the percentiles are calculated for each calendar day and each weather station using a 15-day window-centered method. The probability density function is computed for the day $X$ using the temperature data of the 65 year climatology between $X-7$ days and $X+7$ days. For example, to compute the 95th percentile on 20 August at a given weather station, we used the local $\mathrm{T}_{\text {MAX }}$ values between 13 and 27 August of the 65 years between 1951 and 2015 (Fischer and Schär 2010; Stefanon et al. 2012; Perkins and Alexander 2013).

Warm and cold spells are most often defined as continuous series of days with an exceptionally high or low air temperature. Their minimum duration varies depending on the purpose of the given research study (Perkins 2015), although in climatological research, it is often assumed that this duration should equal at least 3 days (Nairn and Fawcett 2011; Perkins and Alexander 2013). In this study, it is assumed that WS equals at least three consecutive WDs, and analogously CS equals at least three consecutive CDs.

Temperature extremes may produce negative impacts on human life and man's economic activity during any season of the year including increased mortality and morbidity as well as losses in agriculture and forestry. The most dangerous extremes are warm extremes in the summer and cold extremes in the winter (Domonkos et al. 2003 and references therein), and these extremes are examined in this study. The relatively strict criteria applied for determining WSs and CSs allowed to identify only major events which are presumed to have significant impacts on the natural environment and society.

The first stage of the study involved the examination of multiannual variability of the mean $\mathrm{T}_{\text {MAX }}$ and $\mathrm{T}_{\text {MIN }}$ in the summer (JJA) and winter (DJF) using a linear regression function. Given that both the slope and significance of trends strongly depend on the choice of study period, the temporal variability analysis for air temperature was enhanced with running trend analysis previously used, e.g., by SanchezLorenzo et al. (2015) and Pfeifroth et al. (2018) for solar radiation and by Wypych et al. (2017) for air temperature. This approach makes it possible to closely track changes in temperature for each multiannual sub-period of interest as well as to compare results with other studies. The statistical significance of trends was assessed using Student's $t$ test at the level $\alpha=0.05$. The next stage of the study consisted of temporal and spatial analysis of the following:

- frequency of the occurrence of warm and cold extremes

- duration of WSs and CSs (number of days)
- $\quad$ severity of warm and cold extremes $\left({ }^{\circ} \mathrm{C}\right)$

- highest $\mathrm{T}_{\text {MAX }}$ and lowest $\mathrm{T}_{\mathrm{MIN}}$ during warm and cold extremes $\left({ }^{\circ} \mathrm{C}\right)$

Severity of summer warm extremes was characterized for each season and each weather station using the cumulative temperature excess above the 95th percentile (TS95):

$\mathrm{TS} 95=\sum_{i=1}^{N}\left(T_{\mathrm{MAX}}-T_{\mathrm{MAX}} 95\right)$

where $T_{\mathrm{MAX}}$ is the maximum daily air temperature, $T_{\mathrm{MAX}} 95$ is the corresponding 95th percentile, and $N$ is number of days when $T_{\text {MAX }}>T_{\text {MAX }} 95$ in a season (based on Kyselý 2010 and Wypych et al. 2017). Severity of winter cold extremes (cumulative temperature excess below the 5th percentile; TS5) was computed analogously, but absolute values were used for the daily minimum temperature $\left(T_{\mathrm{MIN}}\right)$ and the corresponding 5 th percentile $\left(T_{\mathrm{MIN}} 5\right)$, and hence, $N$ is the number of days when $\left|T_{\mathrm{MIN}}\right|>\left|T_{\mathrm{MIN}} 5\right|$ in a season:

$\mathrm{TS} 5=\sum_{i=1}^{N}\left(\left|T_{\mathrm{MIN}}\right|-\left|T_{\mathrm{MIN}} 5\right|\right)$

TS95 and TS5 multiannual variability was examined using linear regression function, and the statistical significance of trends was assessed using Student's $t$ test at the level $\alpha=$ 0.05. WDs and CDs trends were determined using the nonparametric Kendall test that serves to analyze data with a distribution different from a normal distribution, and their statistical significance was assessed using Sen's slope estimator at the level $\alpha=0.05$. WSs and CSs trends were not calculated due to an inadequate number of cases.

Studies on the role of atmospheric circulation in the occurrence of temperature extremes rely on a number of different research methods. Some researchers choose to use atmospheric circulation indices such as ENSO, PDO, Pacific/North American pattern (PNA), and Arctic Oscillation (AO) (Papineau 2001; Kenyon and Hegerl 2008; L'Heureux et al. 2010). Circulation pattern classifications are also becoming increasingly popular and are available for Alaska in Cassano et al. (2006, 2016a, b) thanks to the use of a self-organizing map (SOM) framework. Another approach used in the present study consists of circulation or advection-type classifications that may be created in an objective or subjective manner (Kyselý 2008, 2010; Ustrnul et al. 2010). In this study, in order to characterize synoptic conditions during WDs, WSs, CDs, and CSs, the objective classification scheme of advection types by Ustrnul (1997) was employed. This method uses the methodology of the objective classification scheme of daily atmospheric circulation devised by Jenkinson and Collison (1977) and based on Lamb weather types (Lamb 1972; Jones et al. 2014). Advection types are specified at individual grid points located nearest to each of 
10 weather stations. They are determined on the basis of predominant air advection as expressed by a geostrophic wind vector as well as types of pressure systems. Advection types are therefore distinguished on the basis of three variables: (i) wind velocity at the $850 \mathrm{hPa}$ isobaric level (v), (ii) wind direction at the $850 \mathrm{hPa}$ isobaric level (d), (iii) sea level pressure (SLP; criteria shown in Table 1). A total of 18 advection types are distinguished based on select assumptions: eight cyclonic, when $\mathrm{SLP} \leq 1013.3 \mathrm{hPa}$ (e.g., northeasterly cyclonic (NEc)); eight anticyclonic, when SLP $>1013.3 \mathrm{hPa}$ (e.g., northeasterly anticyclonic (NEa)); and two non-advectional, when $v<$ $2 \mathrm{~m} / \mathrm{s}$ (i.e., Bc, Ba; Table 1). The assumptions behind this classification scheme are simple, which is why it is universal and may be used for all regions of the northern hemisphere.

In order to concisely present the research results and focus on the main differences for the climatic zones, the results in a graphical format are presented for four weather stations representing different climate regimes: Barrow (Arctic), Fairbanks (continental), Bethel (maritime, strongly influenced by the seasonal distribution of sea ice, and Juneau (temperate maritime) (Fig. 1; Shulski and Wendler 2007).

\section{Results}

\subsection{Temperature variability and trends}

Mean summer $T_{\text {MAX }}$ ranged from approximately $20{ }^{\circ} \mathrm{C}$ in the Interior (McGrath, Fairbanks, Northway) to $16-18{ }^{\circ} \mathrm{C}$ in the south and about $13{ }^{\circ} \mathrm{C}$ at westernmost stations to less than $7{ }^{\circ} \mathrm{C}$ at Barrow (Table 2). On the other hand, mean $T_{\mathrm{MIN}}$ in the winter ranged from less than $-4{ }^{\circ} \mathrm{C}$ at southernmost stations to approximately $-12{ }^{\circ} \mathrm{C}$ at Anchorage and King Salmon and about $-18{ }^{\circ} \mathrm{C}$ at Bethel and Nome to less than $-25{ }^{\circ} \mathrm{C}$ in the Interior

Table 1 Identification criteria for the advection types based on wind velocity and direction at the $850 \mathrm{hPa}$ isobaric level and sea level pressure (Ustrnul 1997)

\begin{tabular}{lllll}
\hline \multicolumn{2}{l}{ Wind at the $850 \mathrm{hPa}$} & & \multicolumn{2}{l}{ Sea level pressure } \\
\cline { 1 - 2 } \cline { 5 - 5 } Velocity (v) & Direction (d) & & $\leq 1013.3 \mathrm{hPa}$ & $>1013.3 \mathrm{hPa}$ \\
\hline $\mathrm{v} \geq 2 \mathrm{~m} / \mathrm{s}$ & $337.5^{\circ} \leq \mathrm{d}<22.5^{\circ}$ & & $\mathrm{Nc}$ & $\mathrm{Na}$ \\
& $22.5^{\circ} \leq \mathrm{d}<67.5^{\circ}$ & & $\mathrm{NEc}$ & $\mathrm{NEa}$ \\
& $67.5^{\circ} \leq \mathrm{d}<112.5^{\circ}$ & & $\mathrm{Ec}$ & $\mathrm{Ea}$ \\
& $112.5^{\circ} \leq \mathrm{d}<157.5^{\circ}$ & & $\mathrm{SEc}$ & $\mathrm{SEa}$ \\
& $157.5^{\circ} \leq \mathrm{d}<202.5^{\circ}$ & $\mathrm{Sc}$ & $\mathrm{Sa}$ \\
& $202.5^{\circ} \leq \mathrm{d}<247.5^{\circ}$ & & $\mathrm{SWc}$ & $\mathrm{SWa}$ \\
& $247.5^{\circ} \leq \mathrm{d}<292.5^{\circ}$ & $\mathrm{Wc}$ & $\mathrm{Wa}$ \\
& $292.5^{\circ} \leq \mathrm{d}<337.5^{\circ}$ & $\mathrm{NWc}$ & $\mathrm{NWa}$ \\
& all & & $\mathrm{Bc}$ & $\mathrm{Ba}$ \\
\hline
\end{tabular}

and Barrow. Both in the summer and winter, the mean diurnal temperature range (mean $T_{\mathrm{MAX}}$ less mean $T_{\mathrm{MIN}}$ ) is the highest in the Interior and at King Salmon (10 $12{ }^{\circ} \mathrm{C}$ ).

Large differences in the spatial distribution of air temperatures are also visible in the spatial distribution of extreme values. Table 2 lists the highest and lowest percentile-based thresholds ( $T_{\mathrm{MAX}} 95$ and $\left.T_{\mathrm{MIN}} 5\right)$ calculated for every weather station for the summer and winter. The lowest $T_{\mathrm{MAX}} 95$ values are most often detected in late summer, with the exception of early summer for Barrow and Cold Bay, while the highest values are most often noted for early July, with late July and early August in the case of Barrow and Cold Bay. The highest $T_{\mathrm{MIN}} 5$ values in the north and along the western coast are noted in the early winter-and late winter in other regions of Alaska. The lowest $T_{\mathrm{MIN}} 5$ values at most of the weather stations are noted in the first half of January, but in the north and along the western coast in late January and early February. Percentile-based thresholds vary the most in the summer at the Barrow station $\left(12.1^{\circ} \mathrm{C}\right)$, while in the winter, at Barrow and in the Interior $\left(7.2\right.$ to $7.8^{\circ} \mathrm{C}$ ).

Air temperature in Alaska is characterized by significant variability from year to year, although higher variability is noted in the winter than in the summer (Fig. 2). Higher variability is also noted in the Interior relative to the other regions (Fig. 2b). The best linear fit over the period 1951-2015 indicates a statistically significant increase in $T_{\mathrm{MAX}}$, which occurs at the highest rate in the summer at Barrow $\left(0.5^{\circ} \mathrm{C} / 10\right.$ years $)$ and in the winter at King Salmon $\left(1.0^{\circ} \mathrm{C} / 10\right.$ years) and in the Interior (Table 2, Fig. 2a, b). Summer $T_{\text {MIN }}$ tends to decline at most of the studied stations, although the trend is usually statistically insignificant. On the other hand, winter $T_{\mathrm{MIN}}$ increases at almost all of the stations $\left(\max .0 .7{ }^{\circ} \mathrm{C} / 10\right.$ years at King Salmon), and the increase is statistically significant in most cases (Table 2).

In general, the observed warming occurs faster in the winter than in the summer, and also $T_{\mathrm{MAX}}$ increases faster than $T_{\mathrm{MIN}}$, which results in an increase in the mean diurnal temperature range in both seasons. This increase occurs fastest in western Alaska and in the Interior (Table 2, Fig. 2b, c).

Long-term patterns in $T_{\mathrm{MAX}}$ and $T_{\mathrm{MIN}}$ variability in Alaska were produced by calculating trends for multi-year sub-periods of variable length (Fig. 3). The results of this calculation made it possible to observe common characteristics for the state as a whole as well as differences for individual regions. In general, $T_{\mathrm{MAX}}$ tended to decline in the summer until the early 1960 s, while afterwards it tended to increase, with a few cooler periods (Fig. 3a, c). The $T_{\text {MIN }}$ trend for the summer consisted of a decline in most sub-periods, while the only readily observable increases were noted between the years 1970 and 2000 (Fig. 2). The 
Table 2 Mean $T_{\mathrm{MAX}}$, mean $T_{\mathrm{MIN}}$, linear regression coefficients ( $\Delta T_{\mathrm{MAX}}, \Delta T_{\mathrm{MIN}} ;^{\circ} \mathrm{C} / 10$ years), and highest and lowest percentile-based thresholds ( $T_{\mathrm{MAX}} 95$ and $\left.T_{\mathrm{MIN}} 5\right)$ for the summer (JJA) and winter (DJF) for Alaska (1951-2015)

\begin{tabular}{|c|c|c|c|c|c|c|c|c|c|c|c|c|}
\hline \multirow[t]{3}{*}{ Weather station } & \multicolumn{6}{|c|}{ Summer } & \multicolumn{6}{|l|}{ Winter } \\
\hline & \multicolumn{4}{|c|}{ Mean seasonal temperature and trend } & \multicolumn{2}{|c|}{$T_{\mathrm{MAX}} 95$} & \multicolumn{4}{|c|}{ Mean seasonal temperature and trend } & \multicolumn{2}{|l|}{$T_{\mathrm{MIN}} 5$} \\
\hline & $T_{\mathrm{MAX}}$ & $T_{\mathrm{MIN}}$ & $\Delta T_{\mathrm{MAX}}$ & $\Delta T_{\mathrm{MIN}}$ & Min. & Max. & $T_{\mathrm{MAX}}$ & $T_{\mathrm{MIN}}$ & $\Delta T_{\mathrm{MAX}}$ & $\Delta T_{\mathrm{MIN}}$ & Min. & Max. \\
\hline Barrow & 6.6 & 0.5 & $0.47^{*}$ & $0.14 *$ & 5.7 & 17.8 & -21.4 & -28.6 & $0.81 *$ & $0.59 *$ & -41.8 & -34.4 \\
\hline Nome & 13.5 & 6.2 & $0.36^{*}$ & -0.06 & 18.0 & 23.9 & -9.5 & -18.2 & $0.66^{*}$ & 0.40 & -35.6 & -28.9 \\
\hline Fairbanks & 21.5 & 9.7 & $0.24 *$ & -0.01 & 22.8 & 29.4 & -15.4 & -26.2 & $0.87 *$ & 0.31 & -45.0 & -37.2 \\
\hline Northway & 20.1 & 7.7 & $* 0.24$ & $-0.16^{*}$ & 22.2 & 27.8 & -19.3 & -29.2 & $0.87 *$ & $0.57^{*}$ & -48.9 & -41.6 \\
\hline McGrath & 19.6 & 8.1 & $0.38^{*}$ & -0.06 & 21.7 & 28.3 & -14.3 & -25.4 & $0.87 *$ & $0.47 *$ & -46.1 & -38.9 \\
\hline Bethel & 16.5 & 7.7 & $0.39 *$ & -0.07 & 19.4 & 25.6 & -9.2 & -17.2 & $0.85^{*}$ & $0.53 *$ & -34.4 & -29.4 \\
\hline King Salmon & 17.3 & 6.9 & $0.31^{*}$ & $-0.14 *$ & 20.8 & 25.6 & -3.6 & -13.1 & $0.97 *$ & $0.65^{*}$ & -33.9 & -28.3 \\
\hline Anchorage & 18.4 & 9.7 & $0.19 *$ & 0.03 & 20.0 & 24.4 & -3.9 & -11.7 & $0.64 *$ & $0.57 *$ & -26.7 & -20.6 \\
\hline Cold Bay & 12.6 & 7.2 & $* 0.28$ & -0.05 & 14.0 & 18.3 & 1.3 & -4.1 & $0.37 *$ & -0.03 & -15.6 & -9.4 \\
\hline Juneau & 17.7 & 8.7 & $* 0.19$ & $* 0.15$ & 21.1 & 26.1 & 0.7 & -4.8 & $0.57 *$ & $0.39 *$ & -20.0 & -15.0 \\
\hline
\end{tabular}

*Statistically significant at $\alpha<0.05$

$T_{\mathrm{MAX}}$ and $T_{\mathrm{MIN}}$ trends for the winter were largely the same, but the magnitude of $T_{\text {MAX }}$ was usually higher (Fig. 2). A strong statewide cooling period was observed in the following two sub-periods: $1956 / 57$ to $1975 / 76$ and $1976 / 77$ to 2000/01 (Fig. 3b, d). This illustrates the effect of an unusually warm winter in 1976/77 on the results of trend analysis (Figs. 2 and 3b, d). A rapid decline in air temperature also occurred in the first decade of the twenty-first century, especially in the winter, which may be observed for all weather stations except Barrow, where air temperature values were characterized by uninterrupted increases since the mid-1980s (Figs. 2 and 3b, d).
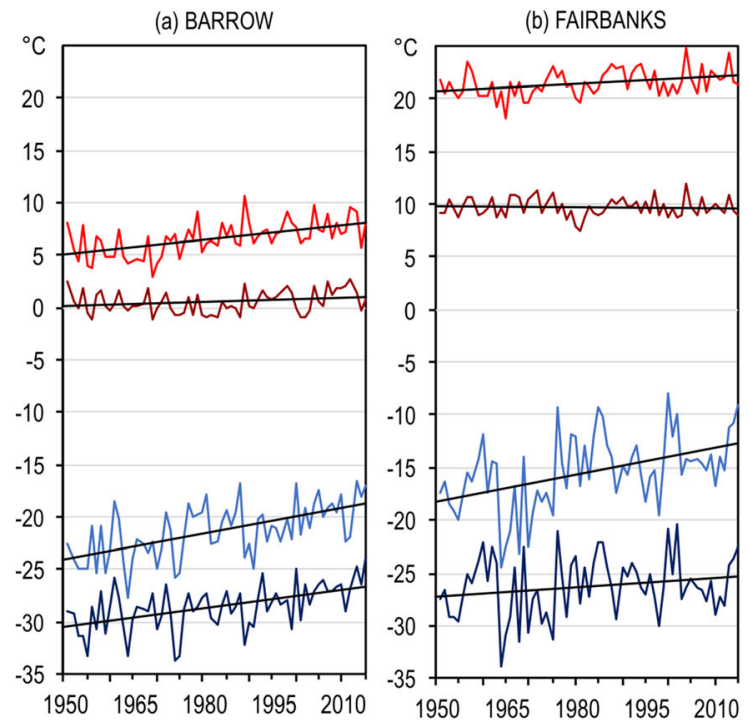

\subsection{Summertime temperature extremes}

\subsubsection{Temporal and spatial variability}

An average of four WDs occurred at each weather station per season, while their maximum number in one summer ranged from 15 at Nome to 30 at Cold Bay (Table 3). The number of WSs at most stations ranged from 30 to 34, with the exception being Juneau at 42; their maximum number per one season ranged from 3 to 6 at Cold Bay (Table 3).

The share of WDs in the formation of WSs was greatest at weather stations located farthest to the east (54 and 55\%),
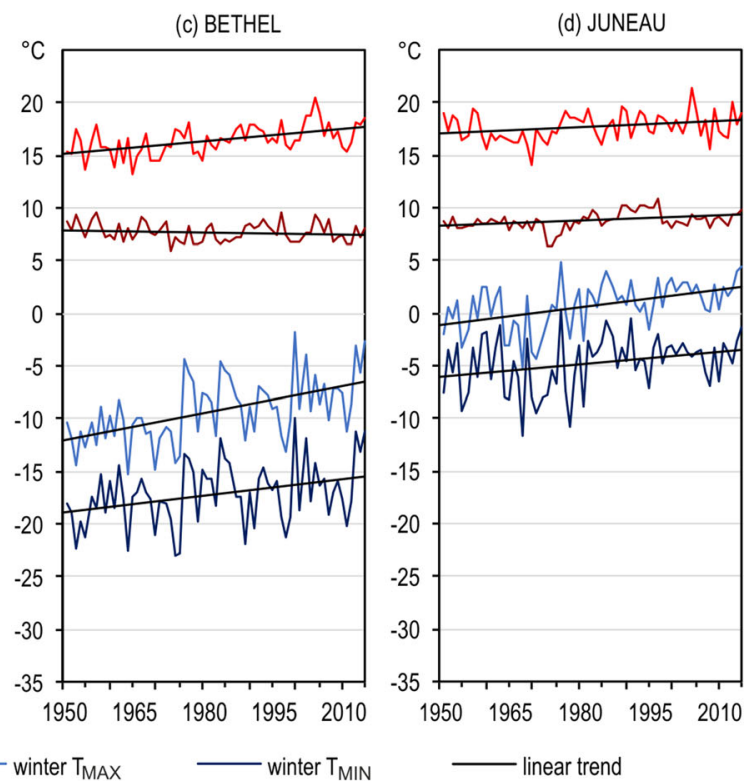

Fig. 2 Summer (JJA) and winter (DJF) $T_{\mathrm{MAX}}$ and $T_{\mathrm{MIN}}$ variability at (a) Barrow, (b) Fairbanks, (c) Bethel and (d) Juneau together with linear trends over the study period (1951-2015). Winter temperatures are assigned to the year of December 


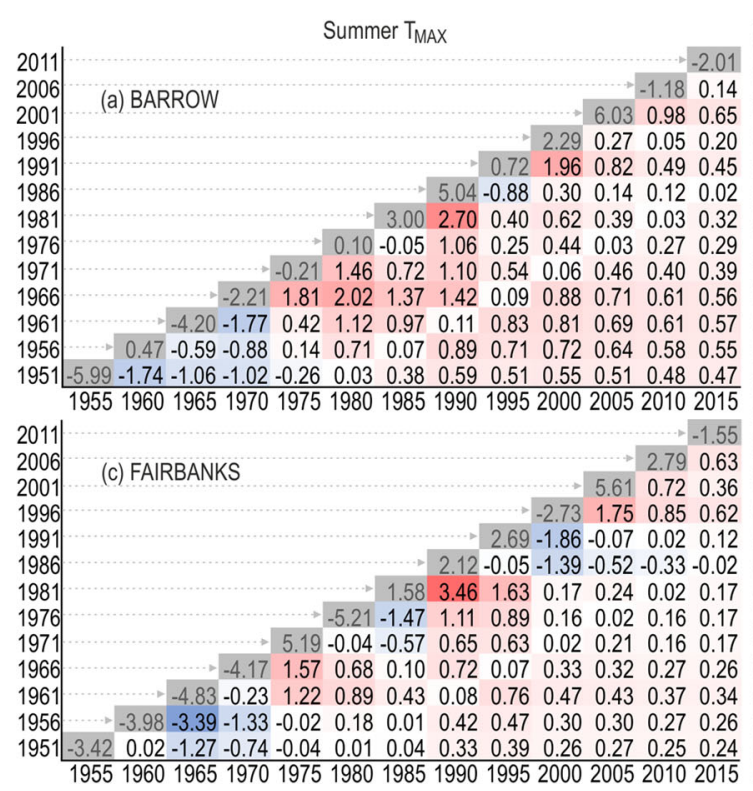

Fig. 3 Running trend analysis of mean summer (JJA) $T_{\mathrm{MAX}}$ and winter (DJF) $T_{\mathrm{MIN}}\left({ }^{\circ} \mathrm{C} / 10\right.$ years) at (a, b) Barrow and (c, d) Fairbanks for successive multi-year periods. Years on the $y$-axis represent the beginning, and

somewhat smaller in the Interior and southern and western Alaska, and the smallest at Barrow (40\%) (Table 3). Data for all weather stations indicate that WSs occurred during all summer months, with the largest number occurring in July (124) followed by August (110) and June (104).

The long-term pattern of WDs and WSs variability differed significantly for each weather station (Fig. 4). A positive WDs trend was noted only in the north and at some stations in the west - statistically significant at Nome and Barrow, reaching 0.7 WD per 10 years (Table 3 ). No trend was detected for the remaining stations, while summer seasons with a large

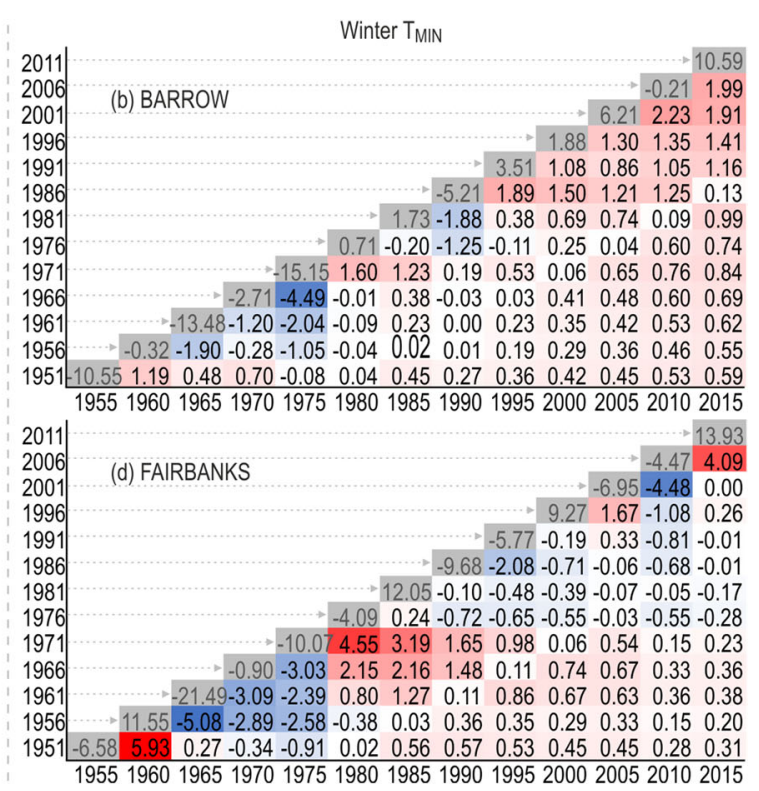

years on the $x$-axis represent the end of the period for which a trend is calculated. Winter temperatures are assigned to the year of December. Colors correspond to positive (red) and negative (blue) trend values

number of WDs and WSs occurred in different years depending on region. At the beginning of the study period, many warm extremes were noted in southern and central Alaska (Fig. 4b, d), while in the 1970s and early 1980s at stations located farthest east and west (Fig. 4d). The 1990s were characterized by a relatively large number of WDs at Barrow and Fairbanks (Fig. 4a, b). Between 2000 and 2015, summers with a relatively large number of warm extremes were noted in all regions of the state. In addition, each weather station recorded a season with the largest number of warm extremes during the same period of time. An exceptionally large number, and in

Table 3 Characteristics of summer warm extremes in Alaska (1951-2015); $\Delta$ WDs - change in the number of WDs per 10 years, $\Delta$ TS95-change in the TS95 per 10 years

\begin{tabular}{|c|c|c|c|c|c|c|c|c|c|}
\hline Station & $\begin{array}{l}\text { WDs max. } \\
\text { number (year) }\end{array}$ & $\begin{array}{l}\text { WDs share in } \\
\text { WSs formation (\%) }\end{array}$ & $\Delta \mathrm{WDs}$ & $\begin{array}{l}\text { WSs total } \\
\text { number }\end{array}$ & $\begin{array}{l}\text { WSs max. } \\
\text { number (year) }\end{array}$ & $\begin{array}{l}\text { Long } \\
\text { days }\end{array}$ & $\begin{array}{l}\text { t WS (duration in } \\
\text { d dates of occurrence) }\end{array}$ & $\begin{array}{l}\text { Highest TS } 95 \\
\left({ }^{\circ} \mathrm{C} \text {; year }\right)\end{array}$ & $\Delta \mathrm{TS} 95\left({ }^{\circ} \mathrm{C}\right)$ \\
\hline Barrow & 17 (2004) & 40 & $0.7 *$ & 33 & $3(2012)$ & 5 & $\begin{array}{l}\text { Aug. 27-31,1974 } \\
\text { Jun. 1-5, 1983 } \\
\text { Jun. 16-20, } 2004 \\
\text { Jul. 23-27, } 2004\end{array}$ & $42.2(2004)$ & $2.0^{*}$ \\
\hline Nome & $15(2004)$ & 43 & $0.6^{*}$ & 30 & 3 (2004) & 8 & Aug. 19-26, 2004 & $60.2(1977)$ & $1.7^{*}$ \\
\hline Fairbanks & $21(2013)$ & 46 & 0.0 & 33 & $3(2004)$ & 7 & Jul. 1-7, 1986 & 36.5 (1994) & 0.2 \\
\hline Northway & $16(2013)$ & 54 & 0.0 & 34 & 3 (2013) & 9 & Jun. 18-26, 2004 & $32.3(2013)$ & 0.4 \\
\hline McGrath & $17(2013)$ & 49 & 0.0 & 34 & $3(2013)$ & 10 & Jun. 4-13, 1957 & 43.3 (1977) & 0.6 \\
\hline Bethel & $22(2004)$ & 48 & 0.2 & 34 & $4(2013)$ & 10 & Aug. 17-26, 2004 & $48.5(2004)$ & $1.5^{*}$ \\
\hline King Salmon & $18(2013)$ & 48 & 0.0 & 33 & $3(1953,2013)$ & 8 & Jun. 14-21, 2015 & $43.1(2015)$ & 0.8 \\
\hline Anchorage & $26(2004)$ & 44 & 0.0 & 31 & $5(2004)$ & 6 & $\begin{array}{l}\text { Jul. 7-12, 2004, } \\
\text { Jun. 14-19, } 2015\end{array}$ & $43.9(2015)$ & $1.4^{*}$ \\
\hline Cold Bay & $30(2014)$ & 45 & 0.0 & 34 & $6(2014)$ & 8 & Aug. 21-28, 1953 & $52.1(1953)$ & 0.4 \\
\hline Juneau & $23(2004)$ & 55 & 0.0 & 42 & $4(2004)$ & 9 & Jun. 18-26, 2004 & $59.7(2004)$ & 0.7 \\
\hline
\end{tabular}

*Statistically significant at $\alpha<0.05$ 

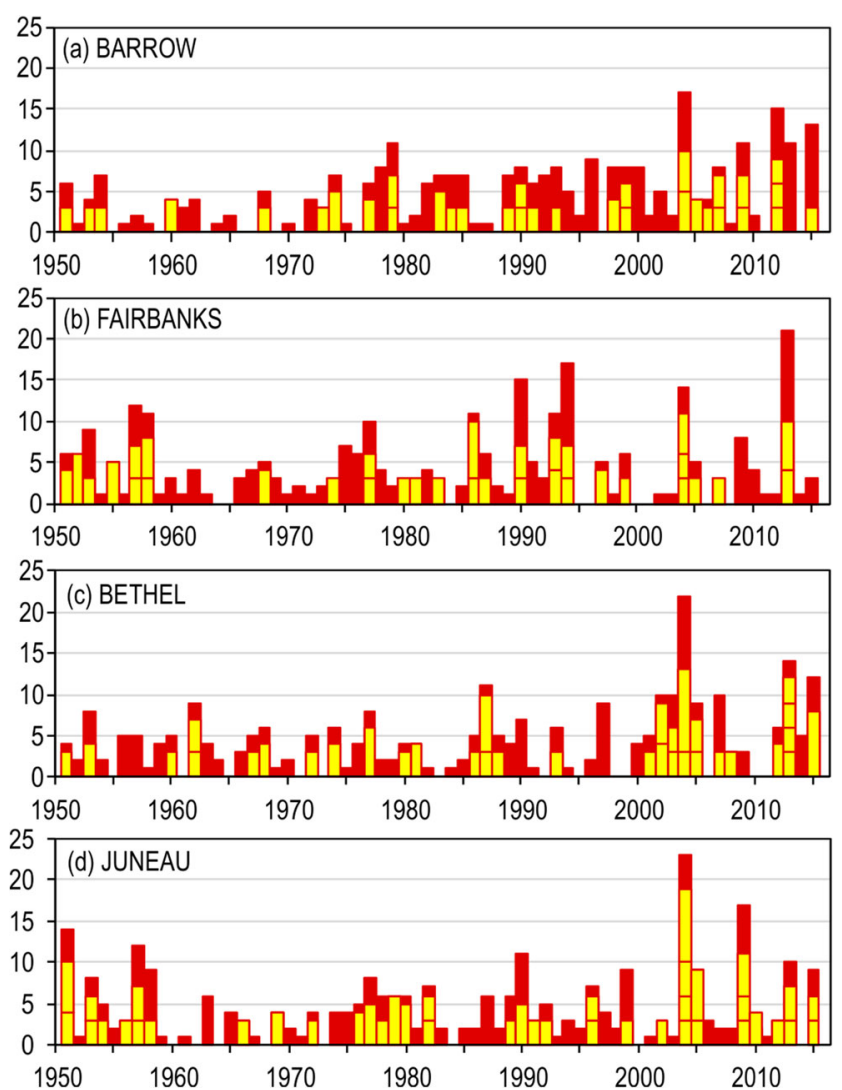

Fig. 4 Number of summer WDs (red bars) and WSs along with their duration (number of days; yellow bars) at (a) Barrow, (b) Fairbanks, (c) Bethel and (d) Juneau (1951-2015)

some instances a record number, of WDs and WSs as well as a long WS total duration was recorded at all stations except Cold Bay in the summer of 2004 (Fig. 4). A large number of WDs and WSs also occurred in the Interior and at Bethel and King Salmon in the summer of 2013 (Fig. 4b, c). Finally, the largest number of warm extremes were noted at Cold Bay in the summer of 2014 (Table 3).

\subsubsection{WS duration}

The most frequently occurring WSs lasted 3 days $(41 \%$ WSs at Northway to $67 \%$ at Barrow) and 4 days (15\% at McGrath to $37 \%$ at Nome). Every weather station recorded at least one 5-day WS (Table 3). WSs lasting 1 week or more occurred mostly in the Interior and in western Alaska. In addition, long duration WSs most often occurred in June and August rather than in July. The longest WSs lasted 10 days and occurred at McGrath and Bethel in the summers of 1957 and 2004, respectively (Table 3 ).

Both longer and shorter WSs occurred throughout the entire study period (Fig. 4). WSs lasting 5 days or more occurred in various years throughout the study period starting with the very beginning of the study period (e.g., Cold Bay, McGrath, Fairbanks, Juneau), through its middle (e.g., Bethel, King Salmon, Fairbanks), and end period (e.g., King Salmon, Anchorage, Northway). More than half the weather stations, scattered throughout Alaska, recorded the longest WS in the summer of 2004, while Anchorage and King Salmon did so in the second half of June 2015. The remaining weather stations recorded their longest WSs in different years (Table 3).

\subsubsection{Severity}

Mean summer TS95 (cumulative temperature excess above the 95th percentile) ranged from $6{ }^{\circ} \mathrm{C}$ at Anchorage and Northway to $9{ }^{\circ} \mathrm{C}$ at Barrow, Nome, and King Salmon. Over the long term, TS95 were strongly associated with the longterm pattern of the occurrence of warm extremes; hence, the number of WDs and WSs usually directly translated into the extremeness of a given summer season (Figs. 4 and 5). A

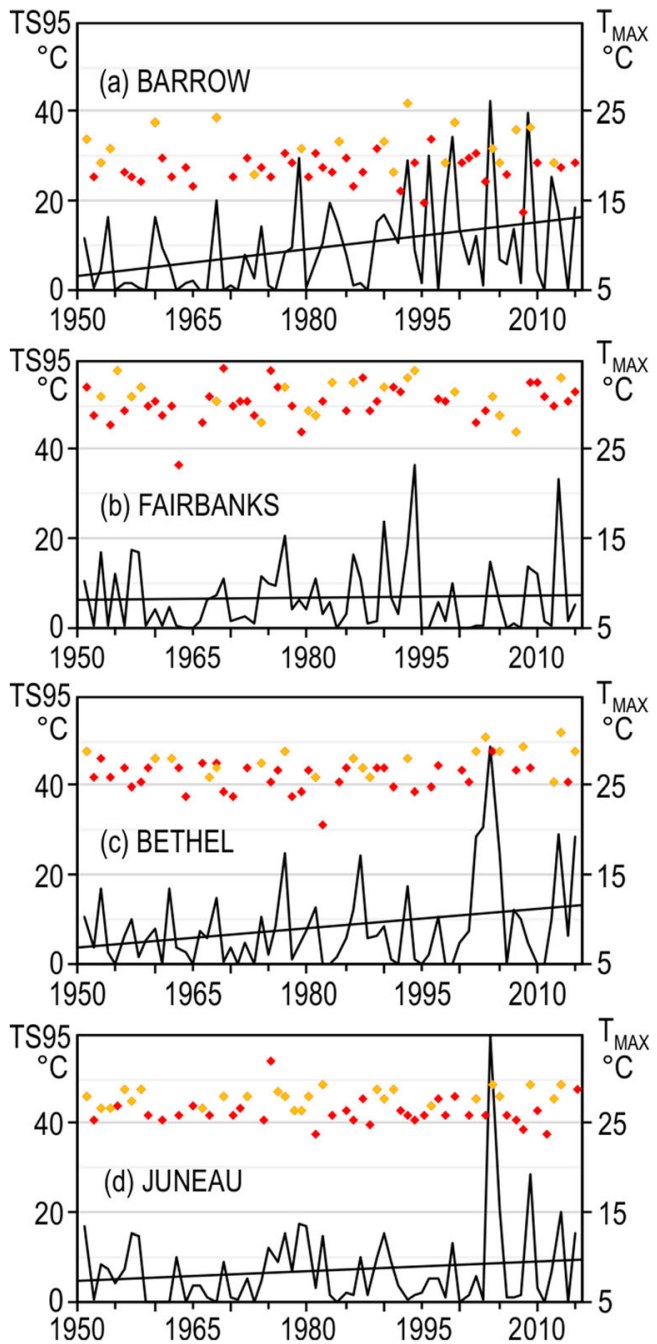

Fig. 5 Cumulative temperature excess above the 95th percentile over the long-term (TS95) and highest daily $T_{\mathrm{MAX}}$ recorded during summer warm extremes in a given season at (a) Barrow, (b) Fairbanks, (c) Bethel and (d) Juneau (1951-2015); red diamonds - $T_{\text {MAX }}$ recorded during a WD, yellow diamonds $-T_{\mathrm{MAX}}$ noted during a WS 
comparison of Figs. 4 and 5 makes it possible to identify seasons characterized by a relatively large number of warm extremes of relatively low severity (e.g., Juneau 1951) as well as those with a relatively small number of WDs and WSs but high severity (e.g., Barrow 1977).

Over the long term, TS95 was characterized by an increase whose largest rate was noted at Barrow, Nome, Bethel, and Anchorage (statistically significant change) and smallest rate in the Interior (Table 3, Fig. 5a-c). The largest TS95 was noted at each weather station during summers with some of the largest, although not necessarily the largest, numbers of warm extremes. The relationship between the highest TS95 and the occurrence of the longest WSs is readily observable - they both occurred at six weather station during the same season (Table 3). The summers characterized by the greatest severity of warm extremes were noted at Nome in 1977 and at Juneau in 2004 (about $60{ }^{\circ} \mathrm{C}$; Table 3, Fig. 5d).

The highest daily $T_{\operatorname{MAX}}$ values exceeded $30{ }^{\circ} \mathrm{C}$ and occurred most often in the Interior, but were also noted in the west (except Cold Bay) and at Juneau (Fig. 5bd). At the Anchorage weather station, $T_{\mathrm{MAX}}$ exceeded $29{ }^{\circ} \mathrm{C}$ only in 1969 , while at Barrow and Cold Bay, it exceeded $25{ }^{\circ} \mathrm{C}$ only in 1960 and 1993 , respectively (Fig. 5a).

Of the highest seasonal $T_{\text {MAX }}$ values noted during warm extremes, anywhere from $30 \%$ (Nome) to $44 \%$ (Juneau, King Salmon) occurred in the course of a WS (Fig. 5).

\subsection{Wintertime temperature extremes}

\subsubsection{Temporal and spatial variability}

An average of four CDs were noted per weather station, but their maximum number per winter ranged from 13 at King Salmon to 25 at Fairbanks (Table 4, Fig. 6b). The number of CSs ranged from 27 at Barrow to 43 at Northway, and their maximum number per season ranged from 2 at King Salmon to 5 at Fairbanks (Table 4).

The share of CDs in CSs formation exceeded $70 \%$ in the Interior and equaled about $60 \%$ in western Alaska, with the exception of Cold Bay, and stood at about $60 \%$ at Anchorage (Table 4). CDs least often formed CSs at Barrow and at stations located farthest to the south. CSs most often occurred in December, with a total of 132 at all weather stations, and in January, with 130, and the least often in February at 92.

A statistically significant decrease in the number of CDs occurred at all stations except for Nome, King Salmon, and Cold Bay, where the number of CDs did not change over the long term (Table 4). The decline in the number of CDs was greatest at Anchorage, with a loss of one CD per 10 years, while at other weather stations, the decline rate ranged from 0.4 to 0.6 per 10 years.

In the early part of the study period, the number of cold extremes in the Interior and at Barrow and Juneau was large (Fig. 6a-d). In the 1960s, a very large number of cold extremes were noted in the Interior and at Anchorage, especially the winters of 1961/62 and 1964/65 (Table 4, Fig. 6b). The

Table 4 Characteristics of winter cold extremes in Alaska (1951/1952-2015/2016); $\Delta$ CDs — change in the number of CDs per 10 years, $\Delta$ TS5 change in the TS5 per 10 years

\begin{tabular}{|c|c|c|c|c|c|c|c|c|c|}
\hline Station & $\begin{array}{l}\text { CDs max. number } \\
\text { (season) }\end{array}$ & $\begin{array}{l}\text { CDs share in } \\
\text { CSs } \\
\text { formation }\end{array}$ & $\Delta \mathrm{CDs}$ & $\begin{array}{l}\text { CSs total } \\
\text { number }\end{array}$ & $\begin{array}{l}\text { CSs max. } \\
\text { number (year) }\end{array}$ & & $\begin{array}{l}\text { lgest CS (duration } \\
\text { lays and dates of } \\
\text { urrence) }\end{array}$ & $\begin{array}{l}\text { Highest TS5 } \\
\left({ }^{\circ} \mathrm{C} \text {; season }\right)\end{array}$ & $\begin{array}{l}\Delta \mathrm{TS} 5 \\
\left({ }^{\circ} \mathrm{C}\right)\end{array}$ \\
\hline Barrow & $24(1974 / 75)$ & 45 & $-0.5^{*}$ & 27 & $3(1983 / 84)$ & 13 & $\begin{array}{l}\text { Dec. 24, 1974-Jan. } \\
\quad 5,1975\end{array}$ & $87.5(1974 / 75)$ & $-3.5^{*}$ \\
\hline Nome & $23(2011 / 12)$ & 64 & 0.0 & 35 & $3(1975 / 76)$ & 16 & Jan. 16-31, 1989 & $89.8(1988 / 89)$ & -0.2 \\
\hline Fairbanks & $25(1964 / 65)$ & 70 & $-0.4^{*}$ & 42 & $5(1964 / 65)$ & 13 & Feb. 4-16, 1979 & $68.5(1964 / 65)$ & $-4.6^{*}$ \\
\hline Northway & $23(1964 / 65)$ & 74 & $-0.5^{*}$ & 43 & $4(1964 / 65)$ & 14 & Feb. 5-18, 1979 & $100.5(1978 / 79)$ & $-3.2 *$ \\
\hline McGrath & $19(1988 / 89)$ & 61 & $-0.5^{*}$ & 36 & $3(1975 / 76,1998 / 99)$ & 17 & $\begin{array}{l}\text { Jan. 16-Feb. 1, } \\
1989\end{array}$ & $101.2(1988 / 89)$ & -1.9 \\
\hline Bethel & $20(1988 / 89)$ & 60 & $-0.5^{*}$ & 36 & $\begin{array}{c}3(1974 / 75,1975 / 76 \\
1988 / 89)\end{array}$ & 17 & $\begin{array}{l}\text { Jan. 16-Feb. 1, } \\
1989\end{array}$ & $93.6(1988 / 89)$ & -2.0 \\
\hline $\begin{array}{l}\text { King } \\
\text { Salmon }\end{array}$ & $13(2005 / 06)$ & 56 & 0.0 & 35 & 2 (several) & 11 & $\begin{array}{l}\text { Jan. 23-Feb. 2, } \\
2006\end{array}$ & $73.9(2005 / 06)$ & 0.4 \\
\hline Anchorage & $20(1961 / 62)$ & 64 & $-1.0 *$ & 36 & $3(1989 / 90)$ & 13 & Dec. $18-30,1961$ & $122.5(1961 / 62)$ & $-3.5^{*}$ \\
\hline Cold Bay & $20(1975 / 76)$ & 41 & 0.0 & 28 & $3(1974 / 75,1975 / 76)$ & 8 & Feb. $18-25,1974$ & $47.9(1974 / 75)$ & 0.9 \\
\hline Juneau & $24(1978 / 79)$ & 49 & $-0.6^{*}$ & 36 & $4(1968 / 69,1978 / 79)$ & 9 & Feb. 7-15, 1979 & $85.4(1978 / 79)$ & $-3.7 *$ \\
\hline
\end{tabular}

*Statistically significant at $\alpha<0.05$ 

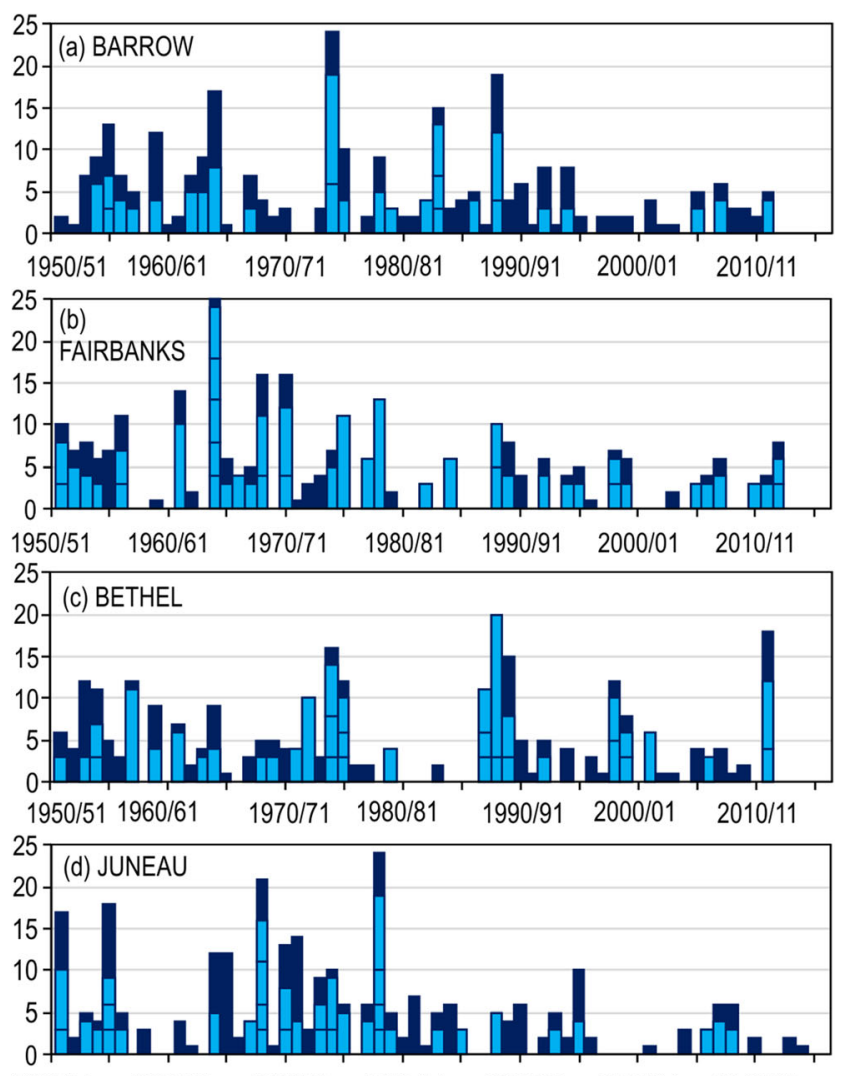

$\begin{array}{lllllll}1950 / 51 & 1960 / 61 & 1970 / 71 & 1980 / 81 & 1990 / 91 & 2000 / 01 & \text { 2010/11 }\end{array}$

Fig. 6 Number of winter CDs (dark blue bars) and CSs along with durations (number of days; light blue bars) at (a) Barrow, (b) Fairbanks, (c) Bethel and (d) Juneau (1951/1952-2015/2016)

1970s were characterized by a large number of CDs and CSs throughout the state, with the coldest winters in 1970/71 (Interior), 1974/75 and 1975/76 (western and northern Alaska), and 1978/79 (eastern Alaska). The winters of 1988/ 89 and 1989/90 were very cold in the western part of the state (Table 4, Fig. 6c), while winters in the late 1990s may be described as rather cold. Since the year 2000, many cold extremes were recorded at King Salmon and Cold Bay, while the only very cold winter season to affect a larger area was that of 2011/12 in western Alaska (Fig. 6c).

\subsubsection{CS duration}

The most frequently occurring CSs lasted 3 days (from $30 \%$ $\mathrm{CS}$ at Barrow to $56 \%$ at Nome), 4 days (from $7 \%$ at Cold Bay to $37 \%$ at Barrow), and 5 days (from $9 \%$ at Northway to $25 \%$ at Cold Bay). Each weather station recorded at least one CS lasting 8 days or more, while 10-day CSs and longer CSs were noted at each station except those located farthest south. The longest CSs lasted 17 days and occurred at Bethel and McGrath in the winter of 1988/89 (Table 4).

Both long and short CSs occurred throughout the multi-year study period (Fig. 6). CSs lasting 6 days or more occurred both in the beginning of the research period (e.g., Bethel, Fairbanks,
Anchorage) and in the middle (e.g., Barrow, Nome, Juneau) as well as towards the end (e.g., Bethel, Nome). The longest CSs at each weather station were noted in the second half of January in 1989 (western Alaska-longest CSs during the study period), in February of 1979 (Interior, Juneau), and in the following seasons: 1961/1962, 1973/1974, 1974/1975, and 2005/2006 (remaining stations; Table 4).

\subsubsection{Severity}

Mean winter TS5 (cumulative temperature excess below 5th percentile) at the studied stations ranged from $10{ }^{\circ} \mathrm{C}$ at Barrow, Cold Bay, Fairbanks, and Nome to $14{ }^{\circ} \mathrm{C}$ at King Salmon. As in the case of warm extremes, the long-term pattern of TS5 reflects the long-term pattern of cold extremes, and in the vast majority of cases, a large number of CSs and CDs per season translate into significant extremeness of the given winter season (Figs. 6 and 7). In some cases, a fairly small number of cold extremes were associated with high severity (e.g., Barrow 1959/1960, Fairbanks 1968/1969) and vice versa; a relatively large number of CDs and CSs was characterized in some cases by low severity (e.g., Bethel 2011/2012).

TS5 for the study period followed a declining tendency at most of the weather stations. The decline rate was highest and statistically significant in the Interior and at Juneau, Anchorage, and Barrow (Table 4, Fig. 7a-d). A statistically insignificant increase in the TS5 was noted at King Salmon and Cold Bay (up to $0.9{ }^{\circ} \mathrm{C} / 10$ years); hence, cold extremes were characterized by increasing severity (Table 4 ). The largest TS5 at each weather station occurred in winters with a large, although often not the largest, number of cold extremes, while at seven stations, this occurred in seasons with the longest CSs (Table 4). The highest TS5 occurred at Anchorage in the winter of $1961 / 62$ (almost $123^{\circ} \mathrm{C}$ ) as well as at McGrath in the winter of 1988/89 and Northway in the winter of 1978/79 (slightly more than $100{ }^{\circ} \mathrm{C}$; Table 4 ).

The lowest daily $T_{\mathrm{MIN}}$ values fell below $-50{ }^{\circ} \mathrm{C}$ in the Interior (down to $-58.9{ }^{\circ} \mathrm{C}$ at McGrath; Fig. 7b). At Barrow, the lowest daily $T_{\mathrm{MIN}}$ fell slightly below $-49^{\circ} \mathrm{C}$ only twice (Fig. 7a). In western Alaska, $T_{\mathrm{MIN}}$ rarely fell below $40{ }^{\circ} \mathrm{C}$ (Fig. 7c), while at Cold Bay, $T_{\mathrm{MIN}}$ rarely fell below $20^{\circ} \mathrm{C}$. The lowest $T_{\mathrm{MIN}}$ values at Anchorage and Juneau were about $-30{ }^{\circ} \mathrm{C}$, although these occurred at Juneau much less frequently (Fig. 7d).

Of the lowest seasonal $T_{\mathrm{MIN}}$ values recorded during cold extremes, between 20\% (Cold Bay) and 68\% (Fairbanks) occurred during a CS (Fig. 7).

\subsubsection{Circulation background}

Figure 8 shows the frequency of WDs for different advection types (ATs) in relation to the total number of days with a given advection type during summer (1979-2015). We combined 


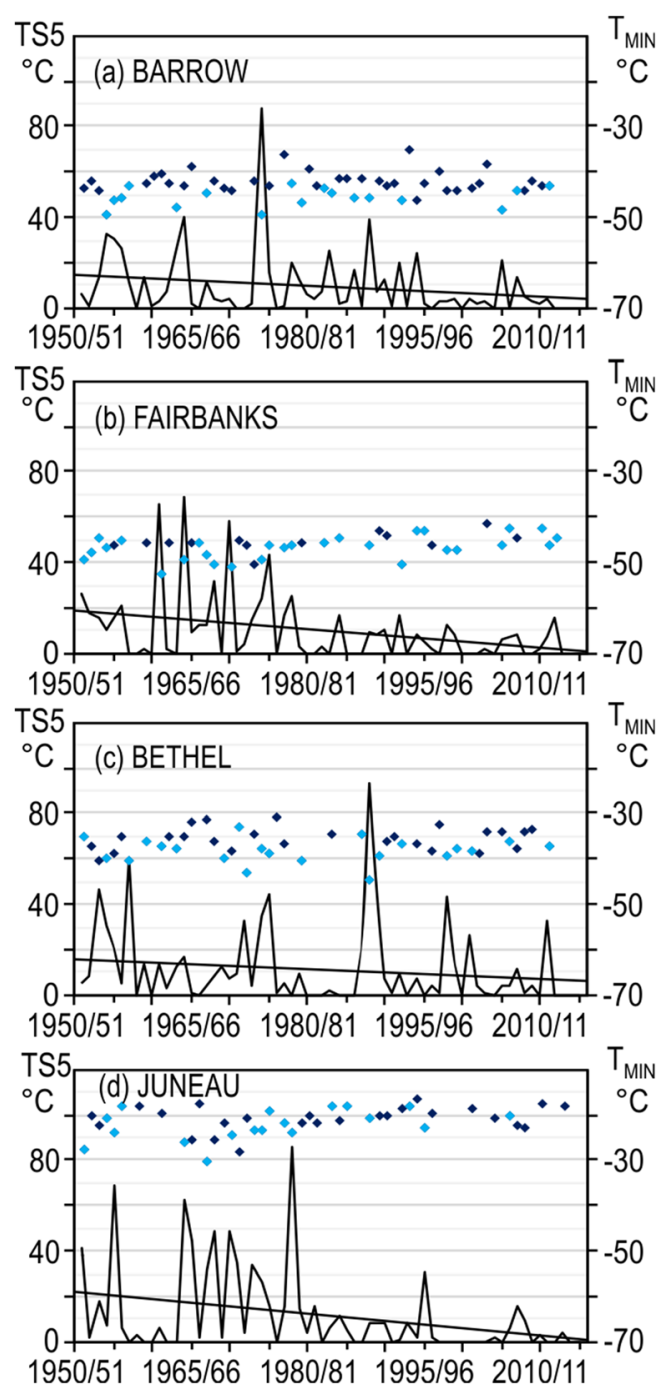

Fig. 7 Cumulative temperature excess below 5th percentile over the long-term (TS5) and lowest daily $T_{\mathrm{MIN}}$ recorded during winter cold extremes in a given season at (a) Barrow, (b) Fairbanks, (c) Bethel and (d) Juneau (1951/1952-2015/2016); dark blue diamonds - $T_{\text {MIN }}$ recorded during a $\mathrm{CD}$, light blue diamonds $-T_{\mathrm{MIN}}$ recorded during a $\mathrm{CS}$

these two characteristics to show indirectly the conditional probability of occurrence of warm extremes for different ATs. Figure 9 is the same but for ATs and CDs in winter.

The occurrence of warm extremes at Barrow independently of pressure systems was accompanied by an influx of air masses from the south and southwest (greatest probability) as well as west and occasionally southeast (Fig. 8a). In the western part of the state, except for Cold Bay, warm extremes occurred most frequently along with advection from the east and to a lesser degree north, although the probability of their actual occurrence was greater for anticyclonic ATs (Fig. 8c). The distribution of warm extremes in the Interior varied strongly for different ATs, occurring at McGrath with different ATs, with the greatest probability for anticyclonic types with advection from the east. The largest number of warm extremes at Fairbanks occurred along with types $\mathrm{Ec}$ and $\mathrm{Bc}$, and while their probability was greatest
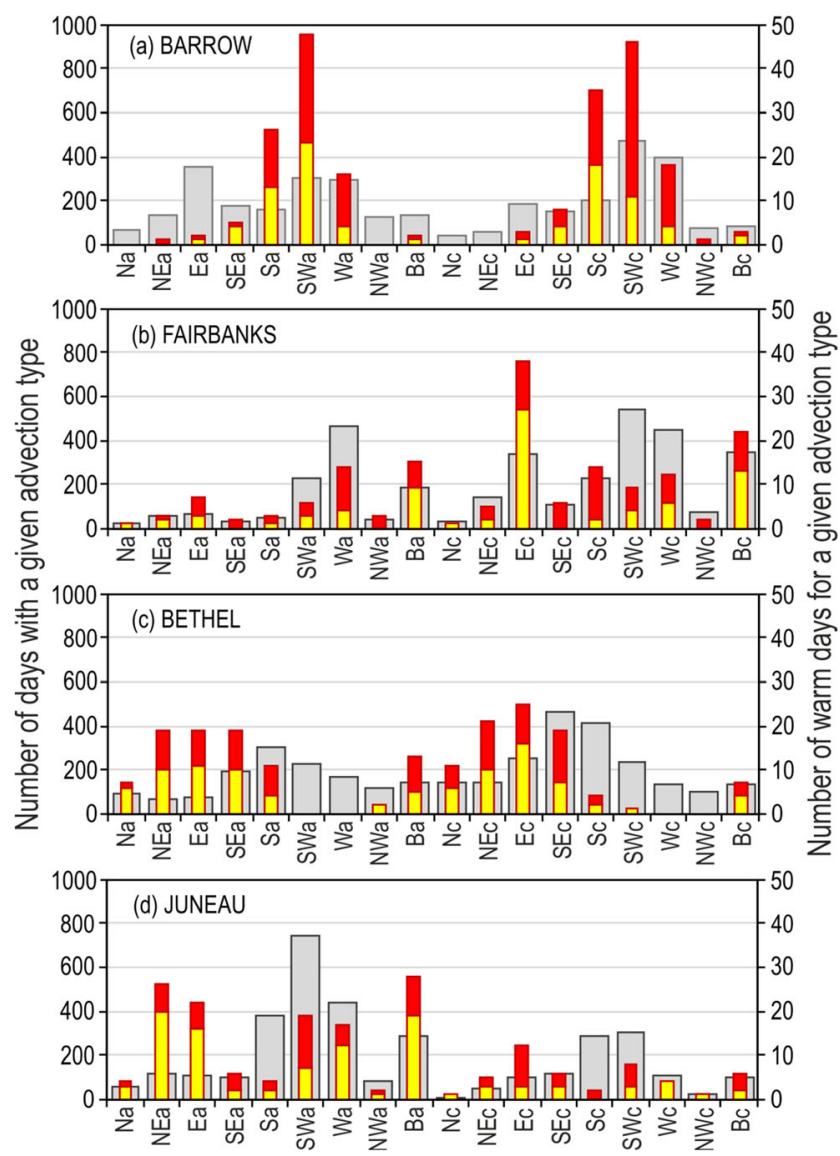

Fig. 8 Number of warm days (red bars - occurring individually and in pairs, yellow bars - triggering warm spells) for individual advection types in relation to the number of days with a given advection type (gray bars) in the summer (JJA) at (a) Barrow, (b) Fairbanks, (c) Bethel and (d) Juneau (1979-2015)

during advection from the east, it was also the least variable among the different ATs present (Fig. 8b). Warm extremes at Northway occurred mainly with advection from the west and with advection-free types, but the greatest probability was noted with types $\mathrm{Sa}, \mathrm{Ea}$, and $\mathrm{Ba}$. At Anchorage, Cold Bay, and Juneau, warm extremes occurred most often along with types characterized by an influx of air masses from the S, SE, N, and NE (Anchorage); Ea, SWa, and Wa (Cold Bay); and NE, E, SWa, and Wa (Juneau), and with advection-free types, although the probability of their occurrence was greatest for types NEa and Ea (Fig. 8d). WSs occurred with both cyclonic and anticyclonic types; the higher probability of their occurrence for anticyclonic types is evident only at the easternmost stations, i.e., Northway and Juneau (Fig. 8d).

Cold extremes at Barrow occurred in the presence of advection from different directions, although more often with anticyclonic than cyclonic types (most favorable type: Bc, Fig. 9a). The occurrence of cold extremes in western Alaska (except Cold Bay) was facilitated by advection from the north and northwest, and especially by anticyclonic ATs (Fig. 9c). In the Interior, cold extremes were accompanied by both cyclonic and anticyclonic 

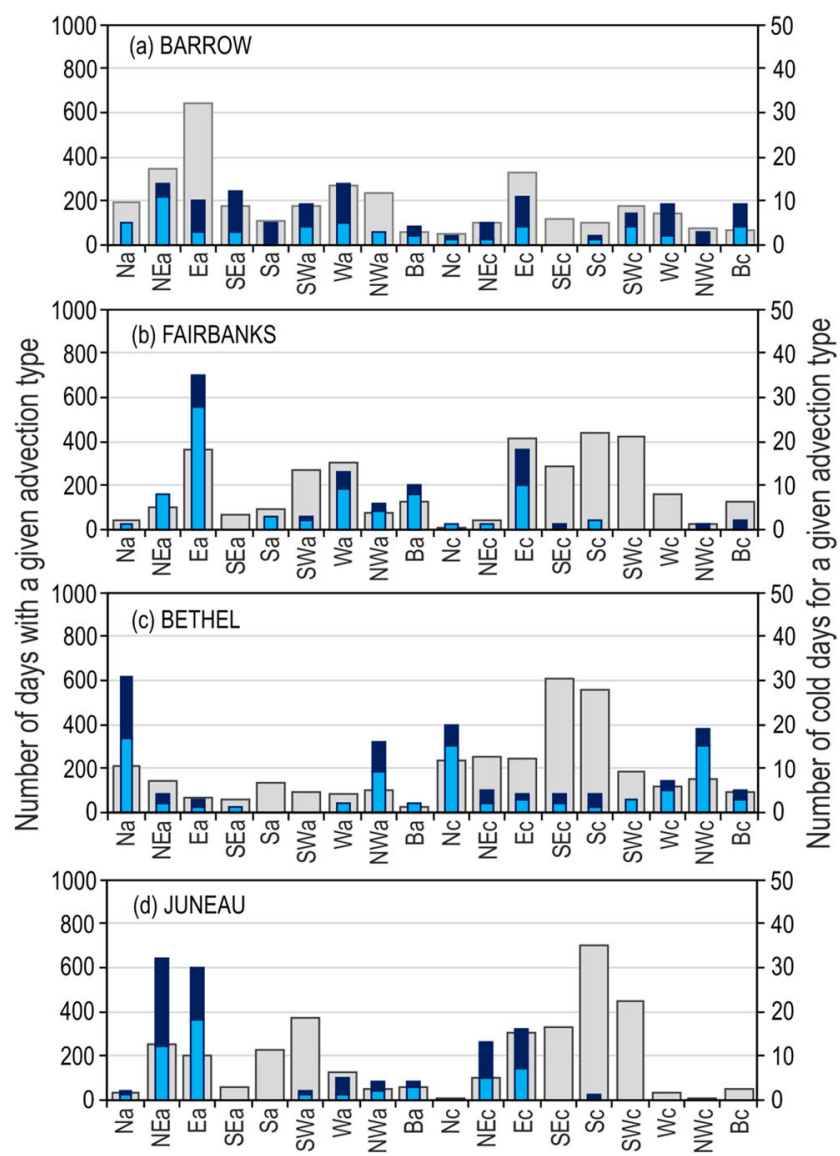

Fig. 9 Number of cold days (dark blue bars - occurring individually and in pairs, light blue bars - triggering cold spells) for specific advection types in relation to the number of days with a given advection type (gray bars) in the winter (DJF) at (a) Barrow, (b) Fairbanks, (c) Bethel and (d) Juneau (1979/1980-2015/2016)

types with advection from the northeast (especially at McGrath), east (Fairbanks, Northway), and the SEa type (Northway), with the greatest probability of their occurrence being associated with types NEa and Ea (Fig. 9b). Cold extremes at Cold Bay occurred most often along with cyclonic types with advection from the north; however, type Ea was most favorable. The occurrence of cold extremes at Anchorage was favored with advection from the north and northeast, while the probability of their occurrence was similar to that for ATs with an influx of air masses from the north. Cold extremes at Juneau were facilitated by advection from the east and northeast (Fig. 9d), and this is especially true of anticyclonic ATs. CSs occurred with both cyclonic and anticyclonic types; however, the probability of their occurrence is generally higher for anticyclonic types. This is especially evident in the Interior (Fig. 9b).

\section{Summary and discussion}

The study focused on the analysis of variability in $T_{\mathrm{MAX}}$ and $T_{\mathrm{MIN}}$ over the long term in the summer and winter as well as warm extremes in the summer and cold extremes in the winter in Alaska in the years 1951-2015. It also focused on an assessment of the relationship between the occurrence of temperature extremes and atmospheric circulation types considering jointly the direction of the air influx and type of pressure system.

Our research results indicate a high rate of increase in air temperature in the winter. The increase was the highest at King Salmon and Barrow as well as in the Interior (McGrath, Fairbanks, Northway). In the summer, opposing $T_{\mathrm{MAX}}$ and $T_{\mathrm{MIN}}$ trends were identified at many weather stations, while $T_{\mathrm{MAX}}$ values increased at half the rate noted for the winter season; the increases were the fastest at Barrow, Bethel, and McGrath. In the case of both the winter and summer, warming occurred faster with $T_{\mathrm{MAX}}$ than with $T_{\mathrm{MIN}}$; the warming was statistically significant for all the weather stations in the study only for $T_{\mathrm{MAX}}$. This study proves results published by Bieniek et al. (2014) who examined changes in the mean seasonal air temperature for 13 climate divisions in Alaska for the period 1949-2012 and found that winter warming occurred roughly twice as fast as in the summer, and areas affected by the highest rate of warming were identical with the areas described above. It is worth noting, however, that the coastal areas of the Beaufort and Chuckchi seas (e.g., Barrow) show the highest rate of temperature increase rather in autumn than in summer or winter (Bieniek et al. 2014). This autumn warming corresponds with the extreme summer sea ice retreat north of Alaska in recent years (Stroeve et al. 2012).

Observed changes in air temperature in the period 19512015 were nonlinear with several multi-year variations. The negative trend noted at the beginning of the study period was interrupted by a marked jump in air temperature (especially in winter) in late 1976 and early 1977 followed by a continuation of the negative trend. Observations such as these confirm findings by Hartmann and Wendler (2005a) who linked this temperature jump with a phase change in the Pacific Decadal Oscillation (PDO), which changed from predominantly negative to predominantly positive in the mid-1970s. Hartmann and Wendler (2005a) were able to show that the positive phase of the PDO is associated with a deeper than normal Aleutian Low, which results in an increased frequency of advection of a relatively warm air mass into Alaska. This also resulted in an increase in annual and seasonal temperatures, mean cloudiness, wind speeds, and precipitation across the state (except for Arctic areas) after the year 1976 (Hartmann and Wendler 2005a). Detailed analysis of air temperature trends made it possible to identify intense cooling in the first decade of the twenty-first century at all studied weather stations except Barrow and was much more pronounced in the winter than in the summer. Wendler et al. (2012) as well as Bieniek et al. (2014) linked this cooling shift with a phase change in the PDO from positive to negative and confirmed its occurrence in all 
regions of Alaska except its Arctic region, which was characterized by an almost constant increase in air temperature.

The temporal variability of air temperature is reflected in changes in the frequency of occurrence of warm and cold extremes and their severity. At the same time, observed air temperature trends indicate that changes in frequency were much more pronounced in the case of cold extremes in the winter versus warm extremes in the summer. The number of warm and cold extremes was characterized by large year-toyear variability. Over the long term, an increase in the number of warm extremes and their severity occurred mainly at Barrow, Nome, and Bethel. In the case of cold extremes, the frequency of their occurrence and their severity declined at all weather stations except these located in the west of the state. Our data may be confirmed using research results published by others. Wendler and Shulski (2009) demonstrated a decrease in the frequency of very cold days or days below $40.0^{\circ} \mathrm{C}$ and an increase in the frequency of very warm days or days above $26.7^{\circ} \mathrm{C}$ at Fairbanks in the period 1906-2006, although the magnitude of change was much larger for the former. Matthes et al. (2015) studied long-term variability in summer warm spells, defined as 6 days with $T_{\text {MAX }}$ greater than the 90th percentile, and winter cold spells, defined as 6 days with $T_{\mathrm{MIN}}$ lower than the 10th percentile, in the Arctic and noted that for Alaska, the trend leans towards warmer air temperatures, especially in the winter and in the northern part of the state.

Our research results made it possible to identify seasons characterized by a large number of severe temperature extremes in Alaska. The summer of 2004 featured the largest number of severe warm extremes at many of the studied stations, especially at Barrow, in the west of the state, and the south of the state, except Cold Bay. Other extreme summer seasons affecting large geographic areas were noted in 1953, 1957, 1977, 1994, 2013, 2014, and 2015. Wendler et al. (2010b) showed that high air temperatures and associated dry conditions may be particularly dangerous in the Interior whose vegetation type and lightning occurrence may lead to destructive wildfires that yield high levels of air pollution and other negative implications. A comparison of multi-year data on warm extremes and the number of wildfires (1955-2009) in the Interior partly reveals this trend, as many wildfires or large total burned areas were noted for the summers of 1957, 1977, and 1990, with a record area burned by wildfires in $2004\left(26,300 \mathrm{~km}^{2}\right.$; Shulski and Wendler 2007; Wendler et al. 2010b). In the case of cold extremes, different winter seasons proved to be the coldest in different regions of Alaska: 1961/1962, 1963/1964, 1974/1975, 1975/ 1976, 1978/1979, 1988/1989, and 2011/2012. Negative effects of long-lasting periods of freezing temperatures include frostbite and high concentrations of pollution from local sources such as power plants, automobile exhaust, and home heating, as well as ice fog that reduces visibility to dangerously low values (Shulski and Wendler 2007).
Research has shown that the occurrence of temperature extremes is generally facilitated by anticyclonic types as opposed to cyclonic types - with advection directions indicating air mass flows from the interior of the North American continent as well as the south (warm extremes in the summer) and north (cold extremes in the winter). Anticyclonic weather suppresses cloudiness, which allows for intensive and extensive sunshine in summer seasons that leads to significant surface heating. However, in the winter, it leads to long-lasting stagnation of the cold air and the emergence of temperature inversions and intensive radiative cooling. The latter is additionally facilitated by low sun angles and high albedo of ground covered with snow. These research findings further confirm findings by Bieniek and Walsh (2017) who analyzed SLP anomalies associated with the top 10 summer highest daily $T_{\mathrm{MAX}}$ and winter lowest daily $T_{\mathrm{MIN}}$ events at Juneau, Anchorage, Nome, Fairbanks, and Barrow (1949-2012). Bieniek and Walsh (2017) emphasize the significance of high pressure systems and temperature advection in the formation of daily temperature extremes. Synoptic patterns leading to the formation of temperature extremes at Barrow during a potentially ice-free period (ASON) were the subject of analysis by Cassano et al. (2006) who also noted a high significance of the advection of warm air masses from the south in the case of warm extremes and advection from the north or the effects of high pressure systems in the case of cold extremes. Cassano et al. (2016a, b) studied the evolution of the atmospheric state leading to the occurrence of extremely high $T_{\mathrm{MAX}}$ values in the summer ( $>99$ th percentile) and extremely low $T_{\text {MIN }}$ values in the winter $(<1$ st percentile) in Alaska south of the Brooks Range excluding the Southeast and Aleutian island chain. For the summer season, they found a high significance of blocking situations and anomalously high surface downward shortwave radiation and temperature advection and anomalously low downward longwave radiation in the winter. According to Athar and Lupo (2010), an exceptionally persistent blocking situation was responsible for the occurrence of extremely warm weather in the summer of 2004.

Atmospheric circulation plays a crucial role in the emergence of temperature extremes in Alaska; however, its effects are strongly affected by various local factors. In the summer, both the intensity and duration of warm extremes are enhanced by the location of weather stations in areas shielded from maritime influence as well as by the formation of a local foehn wind called the chinook. In the winter, the persistence of extremely low temperatures is frequently associated with lowlevel temperature inversion, seasonal sea ice distribution, and local katabatic winds (Shulski and Wendler 2007; Bieniek and Walsh 2017). Inversions separate the boundary layer from the air aloft, which is why they facilitate the persistence of cold air for as long as several weeks. Due to local geographic factors, the region most prone to the occurrence of temperature inversions is the Interior. In fact, work by Hartmann and Wendler 
(2005b) has shown that winter inversions at Fairbanks are semi-permanent.

The effect of sea ice on air temperature is limited to the northern and western coastline of Alaska except for Cold Bay, and its climatologic significance results from its high albedo, insulating properties (reduced energy transfer between the ocean and the atmosphere), and dynamic and thermodynamic properties (Shulski and Wendler 2007). When sea ice covers much of the Bering Sea, the moderating influences of the ocean are very limited, which favors the occurrence of low temperatures, local inversions, and consequently long-lasting CSs. Wendler et al. (2014) showed that in the period 19792012, the sea ice cover on the Bering Sea was characterized by little growth, which contrasts with tendencies observed on the Beaufort Sea and in the Arctic in general. According to Wendler et al. (2014), this is explained by the presence of a negative PDO phase in recent years. It is highly likely that both of these factors were linked with the absence of a decreasing tendency for cold extremes at selected weather stations in western Alaska.

Our research shows that, compared with WDs, CDs were more likely to trigger warm/cold spells, while CSs were more likely to last longer than WSs. Factors facilitating the occurrence of cold extremes, both of the circulation and environmental type, appear to be characterized by greater duration compared with warm extremes, which enables the emergence of extrema and extends their duration.

Bennett and Walsh (2015) generated climate projections for both spatial and temporal changes in extreme temperature events in Alaska in the twenty-first century using global climate models (GCMs). The projections suggest a very rapid increase in air temperature in the future-larger for $T_{\text {MIN }}$ than $T_{\text {MAX }}$-and that changes in extreme air temperatures in the future will be larger in the north during autumn and winter and in the south during spring and summer. Given the negative impacts of temperature extremes and the vulnerability of populations living in distant and poorly accessible areas of Alaska, it is necessary to perform further research on the mechanisms that prompt temperature extremes in order to improve forecasts, adaptation methods, and prevention schemes designed to help reduce negative effects. According to Herman-Mercer et al. (2016) who studied perceptions of climate change by various age groups in indigenous Subarctic communities in Alaska, the formulation of climate change adaptation strategies requires an understanding of the differences in generational observations and perceptions of risk.

\section{Conclusions}

Our analysis and discussion of our research results make it possible to draw the following conclusions:
- Changes in summer and winter $T_{\mathrm{MAX}}$ and $T_{\mathrm{MIN}}$ were nonlinear with several multi-year variations and also highly spatially differentiated. Over the entire study period, the general change pattern was towards the occurrence of warmer temperatures, and the warming was greater in the winter than summer and for $T_{\text {MAX }}$ as opposed to $T_{\text {MIN }}$. Only $T_{\text {MIN }}$ in the summer was characterized by a fairly small and usually statistically insignificant decrease.

- Changes in the frequency of the occurrence of temperature extremes and their severity were much more pronounced in the case of winter cold extremes (decreasing tendencies) than summer warm extremes (increasing tendencies).

- The occurrence of warm extremes in the summer and cold extremes in the winter is generally favored by anticyclonic weather, but the advection direction of air masses is also highly relevant.

- The influence of atmospheric circulation on air temperatures and at the same time on the occurrence of temperature extremes is moderated by various local determinants including local relief, local winds, local thermal inversions, and local sea ice distribution patterns.

- The Interior is the region most susceptible to the negative effects of temperature extremes. The highest $T_{\mathrm{MAX}}$ values in the state occur here in the summer, which also may lead to the occurrence of dangerous wildfires under the right conditions. In the winter, the occurrence of low-level temperature inversions on a regular basis favors the persistence of extremely low temperatures and increases in the concentration of air pollution in excess of acceptable norms.

Funding information This research was co-funded by the Jagiellonian University in Kraków (grant no. K/DSC/004025).

Abbreviations AT, advection type; $\mathrm{CD}$, cold day; CS, cold spell; $\mathrm{T}_{\mathrm{MAX}} 95, T_{\mathrm{MAX}}$ threshold for warm extremes (based on 95th percentile); $\mathrm{T}_{\text {MIN }} 5, T_{\text {MIN }}$ threshold for cold extremes (based on 5 th percentile); TS95, warm extremes severity; cumulative temperature excess over the 95th percentile; TS5, cold extremes severity; cumulative temperature excess below the 5 th percentile; WD, warm day; WS, warm spell

Open Access This article is distributed under the terms of the Creative Commons Attribution 4.0 International License (http:// creativecommons.org/licenses/by/4.0/), which permits unrestricted use, distribution, and reproduction in any medium, provided you give appropriate credit to the original author(s) and the source, provide a link to the Creative Commons license, and indicate if changes were made.

\section{References}

Alexander LV, Zhang X, Peterson TC, Caesar J, Gleason B, Klein Tank AMG, Haylock M, Collins D, Trewin B, Rahimzadeh F, Tagipour A, Rupa Kumar K, Revadekar J, Griffiths G, Vincent L, Stephenson DB, Burn J, Aguilar E, Brunet M, Taylor M, New M, Zhai P, Rusticucci M, Vazquez-Aguirre JL (2006) Global observed changes in daily climate extremes of temperature and precipitation. J 
Geophys Res Atmos 111(D05109). https://doi.org/10.1029/ 2005JD006290

AMAP (2011) Executive summary: snow, water, ice and permafrost in the Arctic (SWIPA). Arctic Monitoring and Assessment Programme (AMAP), Oslo xii + $538 \mathrm{pp}$

Athar H, Lupo AR (2010) Scale analysis of blocking events from 2002 to 2004: a case study of an unusually persistent blocking event leading to a heat wave in the Gulf of Alaska during August 2004. Adv Meteorol 2010:1-15. https://doi.org/10.1155/2010/610263

Barnett AG, Hajat S, Gasparrini A, Rocklöv J (2012) Cold and heat waves in the United States. Environ Res 112:218-224

Bennett KE, Walsh JE (2015) Spatial and temporal changes in indices of extreme precipitation and temperature for Alaska. Int J Climatol 35: 1434-1452

Bieniek PA, Walsh JE (2017) Atmospheric circulation patterns associated with monthly and daily temperature and precipitation extremes in Alaska. Int J Climatol 37:208-217. https://doi.org/10.1002/joc.4994

Bieniek PA, Bhatt US, Rundquist LA, Lindsey SD, Zhang X, Thoman RL (2011) Large-scale climate controls of interior Alaska river breakup. J Clim 24:286-297

Bieniek PA, Bhatt US, Thoman RL, Angeloff H, Partain J, Papineau J, Fritsch F, Holloway E, Walsh JE, Daly C, Shulski M, Hufford G, Hill DF, Gens CS (2012) Climate divisions for Alaska based on objective methods. J Appl Meteorol Climatol 51:1276-1289

Bieniek PA, Walsh JE, Thoman RL, Bhatt US (2014) Using climate divisions to analyze variations and trends in Alaska temperature and precipitation. J Clim 27:2800-2818

Cassano EN, Lynch AH, Cassano JJ, Koslow MR (2006) Classification of synoptic patterns in the western Arctic associated with extreme events at Barrow, Alaska, USA. Clim Res 30(2):83-97

Cassano EN, Cassano JJ, Seefeldt MW, Gutkowski WJ Jr, Glisan JM (2016a) Synoptic conditions during summertime temperature extremes in Alaska. Int J Climatol 37:3694-3713. https://doi.org/10. 1002/joc.4949

Cassano JJ, Cassano EN, Seefeldt MW, Gutkowski WJ Jr, Glisan JM (2016b) Synoptic conditions during wintertime temperature extremes in Alaska. J Geophys Res 121:3241-3262

Cattiaux J, Vautard R, Cassou C, Yiou P, Masson-Delmotte V, Codron F (2010) Winter 2010 in Europe: a cold extreme in a warming climate. Geophys Res Lett 37(20). https://doi.org/10.1029/2010GL044613

Della-Marta PM, Haylock MR, Luterbacher J, Wanner H (2007) Doubled length of Western European summer heat waves since 1880. J Geophys Res 112:D15103. https://doi.org/10.1029/2007JD008510

Domonkos P, Kyselý J, Piotrowicz K, Petrovic P, Likso T (2003) Variability of extreme temperature events in south-Central Europe during the 20th century and its relationship with large-scale circulation. Int J Climatol 23(9):987-1010

Fischer EM, Schär C (2010) Consistent geographical patterns of changes in high-impact European heatwaves. Nat Geosci 3:398-403. https:// doi.org/10.1038/ngeo866

Gil-Alana LA (2012) Long memory, seasonality and time trends in the average monthly temperatures in Alaska. Theor Appl Climatol 108: 385-396

Hartmann B, Wendler G (2005a) The significance of the 1976 Pacific climate shift in the climatology of Alaska. J Clim 18:4824-4839

Hartmann B, Wendler G (2005b) Climatology of the winter surface temperature inversion in Fairbanks, Alaska. Proceedings of the 85th American Meteorological Society Annual Meeting, JP2.26. [Available online at https://ams.confex.com/ams/Annual2005/ webprogram/Paper84504.html]

Herman-Mercer N, Matkin E, Laituri M, Toohey R, Massey M, Elder K, Schuster P, Mutter E (2016) Changing times, changing stories: generational differences in climate change perspectives from four remote indigenous communities in Subarctic Alaska. Ecol Soc 21(3). https://doi.org/10.5751/ES-08463-210328
Hess JC, Scott CA, Hufford GL, Fleming MD (2001) El Niño and its impact on fire weather conditions in Alaska. Int J Wildland Fire 10: 1. https://doi.org/10.1071/WF01007

Huth R, Beck C, Philipp A, Demuzere M, Ustrnul Z, Cahynova M, Kyselý J, Tveito OE (2008) Classifications of atmospheric circulation patterns - recent advances and applications. Ann N Y Acad Sci 1146:105-152

IPCC (2013) Climate change 2013: the physical science basis. Contribution of working group I to the fifth assessment report of the intergovernmental panel on climate change. Cambridge University Press, Cambridge, United Kingdom and New York, USA

Jenkinson AF, Collison FP (1977) An initial climatology of gales over the North Sea. Synoptic Climatology Branch Memorandum No. 62. Meteorological Office, Bracknell, UK

Jeong DI, Sushama L, Diro GT, Khaliq MN, Beltrami H, Caya D (2016) Projected changes to high temperature events for Canada based on a regional climate model ensemble. Clim Dyn 46(9-10):3163-3180

Jones P, Osborn T, Harpham C, Briffa KR (2014) The development of Lamb weather types: from subjective analysis of weather charts to objective approaches using reanalyses. Weather 69(5):128-132

Kenyon J, Hegerl GC (2008) Influence of modes of climate variability on global temperature extremes. J Clim 21(15):3872-3889

Kyselý J (2008) Influence of the persistence of circulation patterns on warm and cold temperature anomalies in Europe: analysis over the 20th century. Glob Planet Chang 62(1):147-163

Kyselý J (2010) Recent severe heat waves in Central Europe: how to view them in a long-term prospect? Int J Climatol 30(1):89-109

Lamb HH (1972) British Isles weather types and a register of daily sequence of circulation patterns, 1861-1971. Geophysical memoir 116. HMSO, London

Lau NC, Nath MJ (2012) A model study of heat waves over North America: meteorological aspects and projections for the twentyfirst century. J Clim 25:4761-4784

L'Heureux M, Butler A, Jha B, Kumar A, Wang W (2010) Unusual extremes in the negative phase of the Arctic oscillation during 2009. Geophys Res Lett 37(10). https://doi.org/10.1029/ 2010GL043338

Mantua NJ, Hare SR, Zhang Y, Wallace JM, Francis RC (1997) A Pacific interdecadal climate oscillation with impacts on salmon production. Bull Am Meteorol Soc 78:1069-1079

Matthes H, Rinke A, Dethloff K (2015) Recent changes in Arctic temperature extremes: warm and cold spells during winter and summer. Environ Res Lett 10. https://doi.org/10.1088/1748-9326/10/11/ 114020

Meehl GA, Tebaldi C (2004) More intense, more frequent, and longer lasting heat waves in the 21st century. Science 305(5686):994-997

Mesinger F, DiMego G, Kalnay E, Mitchell K, Shafran PC, Ebisuzaki W, Jović D, Woollen J, Rogers E, Berbery EH, Ek MB, Fan Y, Grumbine R, Higgins W, Li H, Lin Y, Manikin G, Parrish D, Shi W (2006) North American Regional Reanalysis. Bull Amer Meteor Soc $87: 343-360$

Nairn JR, Fawcett RJ (2011) Defining heatwaves: heatwave defined as a heat-impact event servicing all community and business sectors in Australia. CAWCR technical report No. 060, The Centre for Australian Weather and Climate Research, Australia

Papineau JM (2001) Wintertime temperature anomalies in Alaska correlated with ENSO and PDO. Int J Climatol 21:1577-1592

Perkins SE (2015) A review on the scientific understanding of heatwaves - their measurement, driving mechanisms, and changes at the global scale. Atmos Res 164:242-267

Perkins SE, Alexander LV (2013) On the measurement of heat waves. J Clim 26(13):4500-4451

Perkins SE, Alexander LV, Nairn JR (2012) Increasing frequency. Intensity and duration of observed global heatwaves and warm spells. Geophys Res Lett 39:L20714. https://doi.org/10.1029/ 2012GL053361 
Peterson TC, Heim RR Jr, Hirsch R, Kaiser DP, Brooks H, Diffenbaugh NS, Dole MD, Giovannettone JP, Gurguis K, Karl TR, Katz RW, Kunkel K, Enmaier DL, McCabe GJ, Paciorek CJ, Ryberg KR, Schubert S, Silva VBS, Stewart BC, Vecchia AV, Villarini G, Vose RS, Walsh J, Wehner M, Wolock D, Wolter K, Woodhouse CA, Wuebbles D (2013) Monitoring and understanding changes in heat waves, cold waves, floods, and droughts in the United States: state of knowledge. Bull Am Meteorol Soc 94(6):821-834

Pfeifroth U, Sanchez-Lorenzo A, Manara V, Trentmann J, Hollmann R (2018) Trends and variability of surface solar radiation in Europe based on surface- and satellite-based data records. J Geophys ResAtmos 123:1735-1754. https://doi.org/10.1002/2017JD027418

Porębska M, Zdunek M (2013) Analysis of extreme temperature events in Central Europe related to high pressure blocking situations in 20012011. Meteorol Z 22(5):533-540

Sanchez-Lorenzo A, Wild M, Brunetti M, Guijarro JA, Hakuba MZ, Calbó J, Mystakidis S, Bartok B (2015) Reassessment and update of long-term trends in downward surface shortwave radiation over Europe (1939-2012). J Geophys Res 120:9555-9569. https://doi. org/10.1002/2015JD023321

Schneidereit A, Schubert S, Vargin P, Lunkeit F, Zhu X, Peters DH, Fraedrich K (2012) Large-scale flow and the long-lasting blocking high over Russia: summer 2010. Mon Weather Rev 140(9):29672981

Shevchenko O, Lee H, Snizhko S, Mayer H (2014) Long-term analysis of heat waves in Ukraine. Int J Climatol 34(5):1642-1650

Shulski M, Wendler G (2007) The climate of Alaska. University of Alaska Press, Fairbanks

Shulski M, Walsh JE, Stevens E, Thoman R (2010) Diagnosis of extended cold-season temperature anomalies in Alaska. Mon Weather Rev 138(2):453-462

Stafford JM, Wendler G, Curtis J (2000) Temperature and precipitation of Alaska: 50 year trend analysis. Theor Appl Climatol 67:33-44

Stefanon M, D'Andrea F, Drobinski P (2012) Heatwave classification over Europe and the Mediterranean region. Environ Res Lett 7(1). https://doi.org/10.1088/1748-9326/7/1/014023

Stephenson DB (2008) Definition, diagnosis, and origin of extreme weather and climate events. In: Diaz HF, Murnane RJ (eds) Climate extremes and society. Cambridge University Press, New York
Stroeve JC, Kattsov V, Barrett A, Serreze M, Pavlova T, Holland M, Meier WN (2012) Trends in Arctic sea ice extent from CMIP5, CMIP3 and observations. Geophys Res Lett 39:L16502. https:// doi.org/10.1029/2012GL052676

Ustrnul Z (1997) Variability of the atmospheric circulation on the northern Hemisphere in the 20th Century. Materiały Badawcze IMGW, Seria: Meteorologia 27, Warszawa (in Polish, Eng. summary)

Ustrnul Z, Czekierda D, Wypych A (2010) Extreme values of air temperature in Poland according to different atmospheric circulation classifications. Phys Chem Earth 35:429-436

Vavrus S, Walsh JE, Chapman WL, Portis D (2006) The behavior of extreme cold air outbreaks under greenhouse warming. Int $\mathrm{J}$ Climatol 26(9):1133-1147

Walsh JE, Overland JE, Groisman PY, Rudolf B (2011) Ongoing climate change in the Arctic. Ambio 40:6-16

Wang XL, Feng Y, Vincent LA (2014) Observed changes in one-in-20 year extremes of Canadian surface air temperatures. AtmosphereOcean 52(3):222-231

Wendler G, Shulski M (2009) A century of climate change for Fairbanks, Alaska. Arctic 62(3):295-300

Wendler G, Shulski M, Moore B (2010a) Changes in the climate of the Alaskan North Slope and the ice concentration of the adjacent Beaufort Sea. Theor Appl Climatol 99:67-74

Wendler G, Conner J, Moore B, Shulski M, Stuefer M (2010b) Climatology of Alaskan wildfires with special emphasis on the extreme year of 2004. Theor Appl Climatol 104(3-4):459-472

Wendler G, Chen L, Moore B (2012) The first decade of the new century: a cooling trend for most of Alaska. The Open Atmospheric Science Journal 6:111-116

Wendler G, Chen L, Moore B (2014) Recent sea ice increase and temperature decrease in the Bering Sea area, Alaska. Theor Appl Climatol 117(3-4):393-398

Wendler G, Galloway K, Stuefer M (2016) On climate and climate change of Sitka, Southeast Alaska. Theor Appl Climatol 126:27-34

Wigley TM (1985) Impact of extreme events. Nature 316:106-107

Wypych A, Sulikowska A, Ustrnul Z, Czekierda D (2017) Temporal variability of summer temperature extremes in Poland. Atmosphere 8(3):51. https://doi.org/10.3390/atmos8030051 